Kennesaw State University

DigitalCommons@Kennesaw State University

Dissertations, Theses and Capstone Projects

$12-2014$

\title{
The Role of Preceptorship and Group Cohesion on Newly Licensed Registered Nurses' Satisfaction and Intent to Stay
}

Sarah Michelle Bontrager

Kennesaw State University, schapm28@students.kennesaw.edu

Follow this and additional works at: http:// digitalcommons.kennesaw.edu/etd

Part of the Nursing Administration Commons

\section{Recommended Citation}

Bontrager, Sarah Michelle, "The Role of Preceptorship and Group Cohesion on Newly Licensed Registered Nurses' Satisfaction and Intent to Stay" (2014). Dissertations, Theses and Capstone Projects. Paper 653. 
THE ROLE OF PRECEPTORSHIP AND GROUP COHESION ON NEWLY LICENSED REGISTERED NURSES' SATISFACTION AND INTENT TO STAY

By

SARAH BONTRAGER, BSN, RN

\author{
A Thesis \\ Presented in Partial Fulfillment of Requirements for the \\ Degree of \\ Master's in Nursing Science \\ In the \\ WellStar College of Health and Human Services \\ Kennesaw State University
}

2014 


\section{ACKNOWLEDGEMENT}

When recalling my journey through building and completing my thesis research I would be remiss to ignore the people who have lifted me above all of the stumbling blocks. As a quietly religious person, I would like to thank God for clearing my path and leading me along. I am constantly amazed at the path that God is leading me on.

As a student, I am equally grateful to my thesis advisor, Dr. Patricia Hart. Without your encouragement and constant check-ins I would still be writing my first chapter. Thank you for working with me at the level that I am on and helping me rise to a level that I need to be. I so appreciated all of your gently nudges and pushes to get me to my ultimate goal. Along the same vein, thank you Dr. Mareno for being my second reader and providing amazing support and critical eye to my ever-evolving thesis. You have truly helped elevate it to the next level!

As a part of an amazing family, I am brought to my knees in humility by my family. First to my husband, thank you! You are my constant oasis and I appreciate all of the sacrifices you have made to keep me going; from date nights, to weekends at work. To the constantly forgiving remainder of my family, thank you. Without your constant cheering and understanding it would have been impossible to succeed!

To my WellStar family an equally humbled thank you is due. To Ruth Wingel who is constantly willing to humor my questions for my thesis and for allowing me to take over a few of her classes, thank you! I am constantly grateful for your ear and your encouragement. To Lisa Pruner and Donna Johnson at Kennestone, I appreciate your guidance, encouragement, and warmth. There have been times where those kind words are all that have kept me going. It is so uplifting to get words of encouragement from your mentors and giants. Your encouragement has allowed me to elevate my practice and see the light at the end of the tunnel. 


\section{TABLE OF CONTENTS}

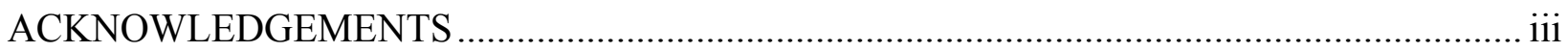

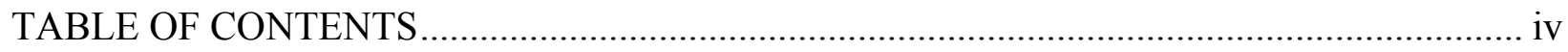

TABLE OF FIGURES ..................................................................................................

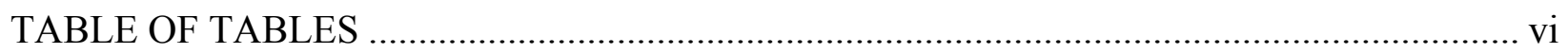

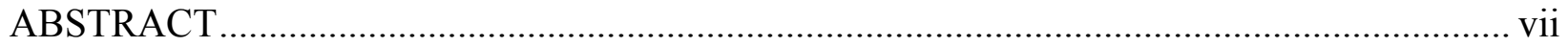

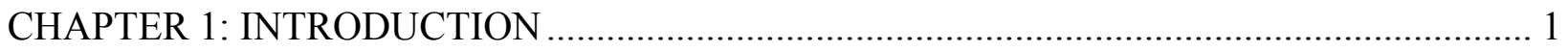

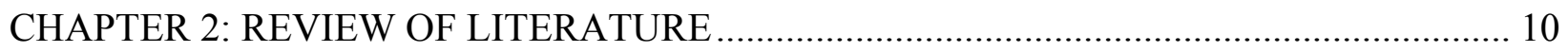

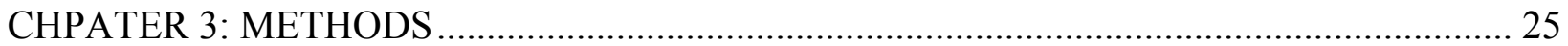

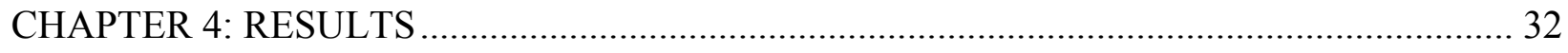

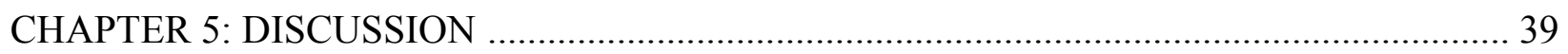

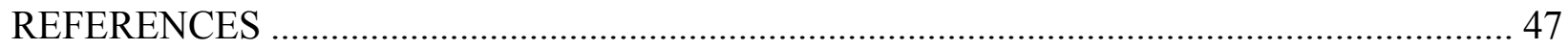

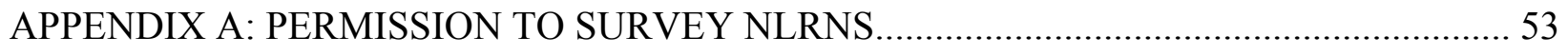

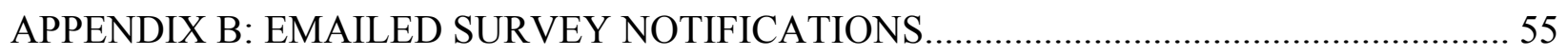

APPENDIX C: DEMOGRAPHIC QUESTIONAIRRE.......................................................... 57

APPENDIX D: PRECEPTOR EFFECTIVENESS SCALE..................................................... 59

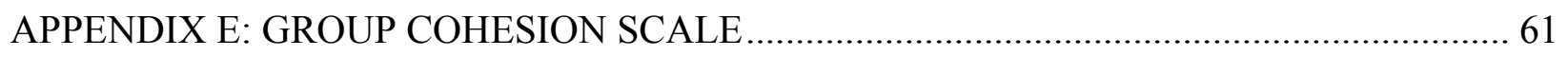

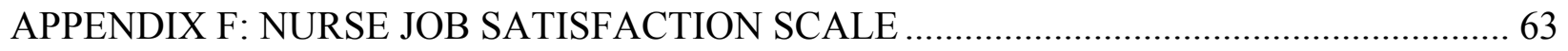

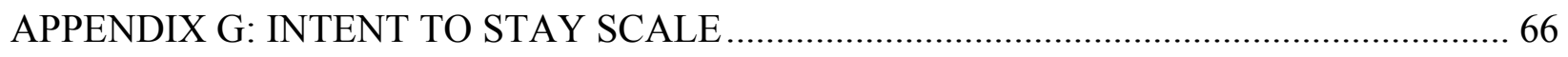

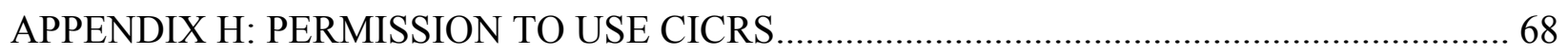

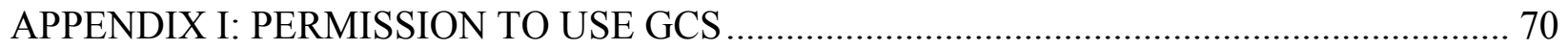

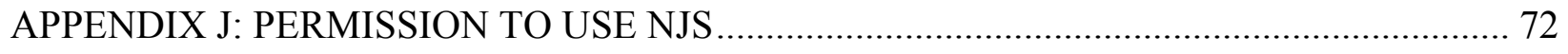

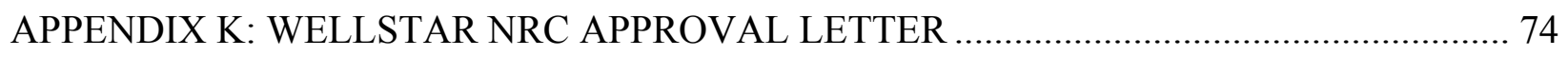

APPENDIX L: KENNESAW STATE IRB APPROVAL LETTER............................................. 76

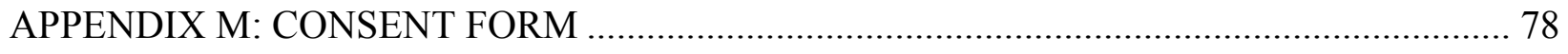




\section{TABLE OF FIGURES}

Figure 1: Cowden and Cumming's Intent to Stay Model .......................................................... 6 


\section{TABLE OF TABLES}

Table 1: Demographic Characteristics of NLRNs ........................................................... 34

Table 2: Score Ranges, Means, and Standard Deviation for the PRES, GCS, JSS, and ITS....... 36

Table 3: Correlation Matrix between PRES, GCS, JSS, and ITS ........................................ 38 


\begin{abstract}
Purpose: The purpose of the study was to understand how preceptor role effectiveness and group cohesion play a role with nursing satisfaction and intent to stay among newly licensed registered nurses.
\end{abstract}

Design: A descriptive, prospective, cross-sectional design was used.

Methods: The newly licensed registered nurse cohorts of a local healthcare system were polled within their first year of practice. The community healthcare system serves five local hospitals and meetings were held at a neutral educational center. A demographic survey as well as surveys on preceptor role effectiveness, perceptions of group cohesion, nursing satisfaction, and intent to stay were used.

Results: NLRNs reported high levels of perceived preceptor role effectiveness $(M=65.37, S D=$ 9.38), group cohesion $(M=32.80, S D=6.67)$, and job satisfaction $(M=80.62, S D=13.91)$. Despite these factors, NLRNs reported only moderate levels of intent to stay $(M=3.30, S D=$ 1.10). Statistically significant relationships were found between preceptor role effectiveness and job satisfaction, $r(84)=0.277, p=0.012$; intent to stay, $r(84)=0.262, p=0.017$; and job enjoyment subscale, $r(84)=0.287, p=0.009$. Statistically significant relationships were found between group cohesion and job satisfaction, $r(84)=0.569, p<0.01$; intent to stay, $r(84)=$ $0.553, p<0.01$; quality of care subscale, $r(84)=0.457, p<0.01$; job enjoyment subscale, $r(84)$ $=0.515, p<0.01$; and time to do job subscale, $r(84)=0.415, p<0.01$.

Conclusion: Effective preceptors and positive group cohesion are factors that are important to NLRNs' job satisfaction and intent to stay. It is important for nursing leaders to identify successful strategies to ease the transition to practice for NLRNs. With proper implementation, nursing leaders can expect some insulation from the global nursing shortage, improved patient outcomes, and increased cost savings from proper NLRN training and retention strategies. 
Keywords: group cohesion, intent to stay, newly licensed registered nurses, nursing satisfaction, preceptor role effectiveness 


\section{CHAPTER 1: INTRODUCTION}

One of the latest tools in combating the nursing shortage has been to refocus on nursing retention. This area is especially important in regards to newly licensed registered nurses (NLRN). NLRN retention ensures a nursing workforce with the longevity to outlast the latest wave of international nursing shortage and global healthcare reform. In efforts to stay competitive and relevant in a health-conscious market, many healthcare systems are offering NLRNs a residency process in order to assure healthcare system-based support and encourage system-specific policy adoption to improve nursing retention. While the NLRN residency process has demonstrated effective in increasing nurse retention and job satisfaction within a healthcare system, (Hillman \& Foster, 2011), more research is needed to determine factors that influence job satisfaction and intent to stay of NLRNs during their transition to practice.

By evaluating factors that influence NLRNs' job satisfaction and intent to stay, an evaluation of NLRNs' perspectives on environmental and practice insight can be made. Factors that need to be further investigated include NLRNs' socialization into the practice environment and preceptor role effectiveness. By understanding NLRNs' perceptions of their socialization into the practice environment and their perceptions of preceptor role effectiveness, strategies and changes can be proposed in order to promote NLRNs' job satisfaction and intent to stay during the transition to practice period.

This chapter describes the purpose, background and significance, the statement of the problem, and the conceptual framework for the study. A discussion of the research questions, limitations, and assumptions along with a list of definitions provides a comprehensive outline of the research study. 


\section{Purpose}

The purpose of this study was to explore the relationships between NLRNs' perceptions of preceptor role effectiveness and perceived levels of group cohesion, job satisfaction, and intent to stay. With these factors more closely evaluated, possible strategies and changes can be addressed to further aid NLRNs' during this challenging transition period. Addressing these factors may also lead to problem-predicting and practice refinement to allow greater job satisfaction and nurse retention.

\section{Background and Significance}

With the nursing shortage potentially leaving healthcare systems 500,000 nurses short by 2025 (Zinn, Gugliemi, Davis, \& Moses, 2012), every effort should be made to retain and hire the most appropriate and adaptable nursing workforce. The shortage also means cultivating and establishing preceptorship and residency programs to train new nurses and ensure that they stay within the healthcare system. The efficacy of the newly licensed registered nurse residency program has already been established (Trepainer, 2012), but efforts must be made to ensure that NLRNs get the system support needed in order to hold the healthcare system accountable for retaining nurses during the first year and beyond. Preparing a framework to aid the NLRN transition to practice as well as improve retention strategies to address the shortage is an important nursing initiative.

NLRNs and experienced nurses alike are currently practicing in the genesis of the latest wave of nursing shortage and every effort must be made to retain the workforce while the shortage grows. With successful retention, this wave of NLRNs will be able to be competent, expert nursing leaders needed during the peak of the shortage (Kowitlawakul, 2013). If these efforts are successful, nursing practice and patient outcomes improve (Burket, Felmlee, Greider, 
Hippensteel, Rohrer, \& Shay, 2010). During the transition to greater accountable, nursing, and results-based care, not only will patient outcomes be improved if greater retention occurs, but healthcare systems will theoretically have improved reimbursement rates. Nursing leadership is charged with implementing improvements in nursing and outcomes-driven care to improve job satisfaction and retention in the NLRN workforce.

\section{Statement of the Problem}

There are copious amounts of resources spent on the new graduate nurse in easing their transition from the graduation platform to the bedside, with the monetary orientation cost estimated to be between $\$ 22,000$ and $\$ 64,000$ for every nurse, regardless of experience (Jones \& Gates, 2007). Furthermore, extra costs are spent in additional staffing and overall support for the NLRN during the orientation period. Support initiatives include effective NLRN residency, preceptorship, and orientation programs prior to full time employment on a nursing unit. These residency, preceptorship, and orientation programs have proven highly effective in reducing new graduate turnover (Trepainer, 2012).

Trepainer reported that first year NLRN turnover reduces from $36.08 \%$ to $6.41 \%$ with the implementation of successful residency, preceptorship, and orientation programs (Trepainer 2012), yet there still seems to be an issue with NLRN turnover immediately following the end of first year residency and its accompanying orientation process. Kovner and colleagues (2007) found that $13 \%$ of newly licensed RNs had vacated their first job after one year, and $37 \%$ reported that they felt ready to change jobs. Turnover includes nurses moving within a system as well as leaving the primary system in which they began their nursing careers. This turnover can lead to consistent and detrimental nursing shortages on nursing units, within a discipline, as well as cost healthcare systems countless orientation resources, including time with preceptors to 
the cost of extra training for the NLRN.

By studying the roles of effective preceptors and group cohesion from a NLRN

perspective one can begin to question their influence on job satisfaction and intent to stay. The four factors of group cohesion, preceptor role effectiveness, nursing satisfaction and intent to stay have been studied as separate entities within the lives of NLRNs but further research is needed to understand the workings of these factors together. With an increased focus on preceptor role effectiveness and group cohesion, the implications of a more supportive transition environment can be uncovered beyond the initial system orientation and residency process. By providing a more supportive transition environment for the NLRN, decreases in staffing shortages, orientation costs, and turnover rates may be experienced. As the global nursing shortage continues, successful transition and socialization strategies are imperative to impact the job satisfaction and retention of NLRNs.

\section{Theoretical and Conceptual Framework}

The theoretical framework that best fit this model of study was Cowden and Cumming's Intent to Stay Model (Cowden \& Cummings, 2012). Figure 1 depicts the Intent to Stay (ITS) model. Cowden and Cummings (2012) developed this model based on the literature identified relationship to ITS, personal experiences, and adaptation of two other models, Boyle et al. (1999) and Tourangeau and Cranley (2006). Cowden and Cummings built the model to allow for the prospective rather than introspective study. By allowing for study of the lived experience as well as accounting for previously studied literature, a thorough study of intent to stay can be gained. The idea behind Cowden and Cumming's model is to allow for synthesis of literature with the lived experience of intent to stay in practice.

Variables included in the model are the manager, organization, work, and nurse 
characteristics (Cowden \& Cummings, 2012). Manager characteristics are the immediate formal level of leadership that act as a liaison to the nurse. The role of the manager in this ITS model can set the tone of the floor of the nurse as well as the ability to engage in the environment of the floor. The perception of organizational characteristics can also be shaped by the manager, but the organization's characteristics must also stretch beyond the management level. In order to completely study this characteristic, the area of organizational characteristics must transcend the micro-level of the practice environment.

Work characteristics are extremely important in the ITS model. Characteristics of this category include abuse, autonomy, and work group characteristics (Cowden \& Cummings, 2012). This category is typically one of the most closely supervised within a healthcare organization and its effects on ITS (Bogeart, Kowalski, Weeks, Heudsen, \& Clarke, 2013).

Closely associated with work characteristics, nursing characteristics also play a large role in ITS within a healthcare setting. Nursing characteristics include age, education level, position preference, tenure, and work status (Cowden \& Cummings, 2012). These nursing characteristics are important in determining ITS for each individual nurse. As observed, any one of these variables can drastically change the ITS for any individual. These characteristics are closely monitored by managers and Executive Directors in order to ensure an appropriate skill mix and determine the potential turnover of staff within a system (Wang, Tao, Ellenbecker, \& Liu, 2012).

With the four characteristics, there are two responses to work that are seen that affect ITS. These two responses are cognitive and affective (Cowden \& Cummings, 2012). The cognitive response to work by the nurse dictates the immediate emotional response to the characteristics as well as the immediate coping mechanisms of the emotional responses. The coping mechanisms include opportunities elsewhere, feelings of empowerment, quality of care, 
and the organizational commitment.

The affective response dictates the more long-term emotional response of physical characteristics. The specific characteristics include moral distress, joy at work, desire to stay, and overall job satisfaction (Cowden \& Cummings, 2012).

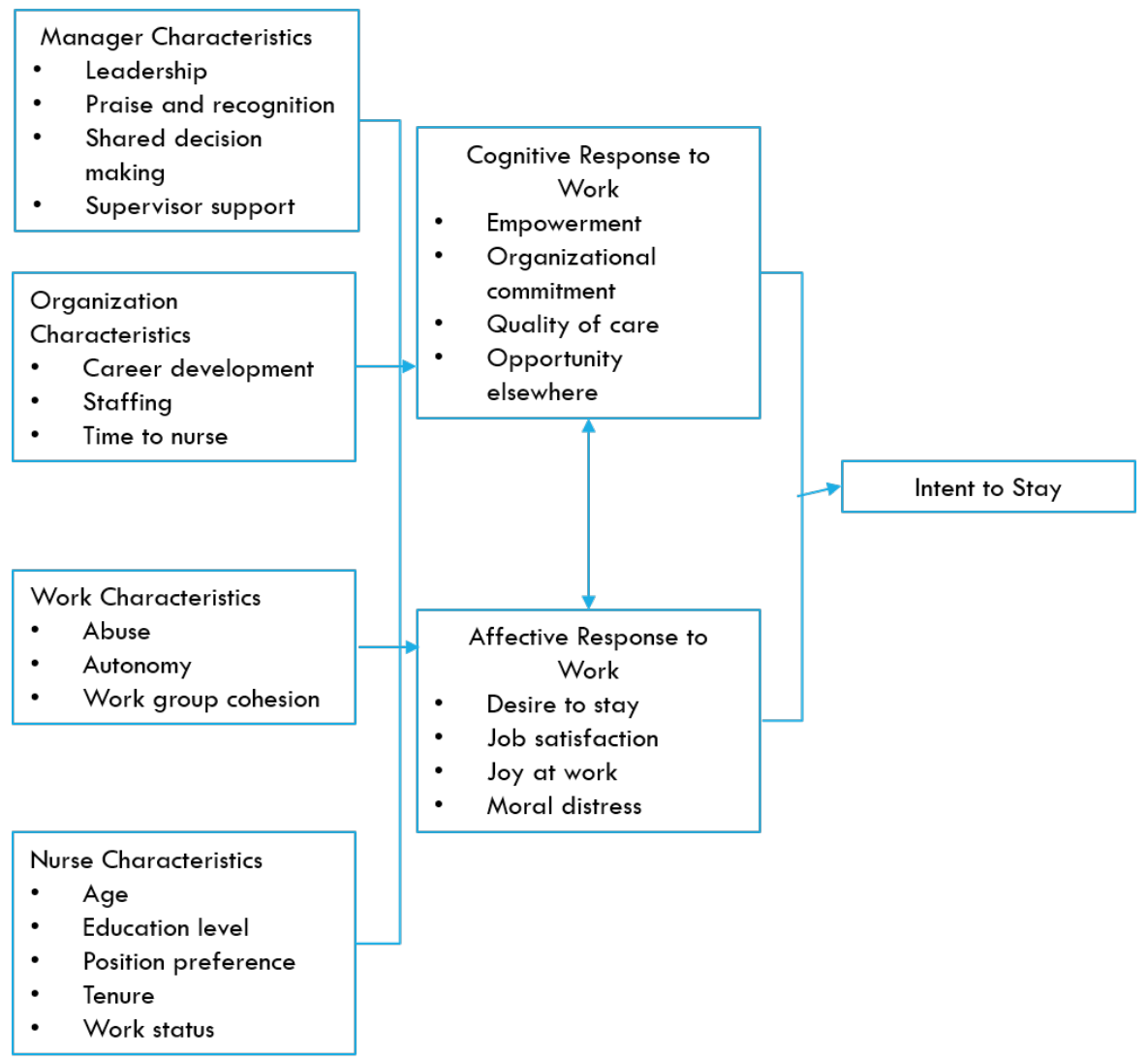

Figure 1: Cowden and Cumming's Intent to Stay Model

A focus of this model that differs from the desired course of research is in regards to the manager characteristics. During the process immediately following orientation in which the NLRN assimilates to practice on the floor the preceptor acts in a more direct managerial role in assisting the NLRN. It is important to understand that the preceptor characteristics are more applicable to study of the NLRN than that of the manager, although managers play important roles further into practice. Because the preceptor's effectiveness will play a more immediate role into the NLRN's early perception of practice the relationship of the preceptor was substituted in 
place of manager characteristics.

\section{Research Questions}

The research questions for this study were:

1) What were the perceived levels of preceptor role effectiveness, group cohesion, job satisfaction, and intent to stay for NLRNs?

2) What were the relationships among preceptor role effectiveness, group cohesion, job satisfaction, and intent to stay among NLRNs?

\section{Conceptual Definitions}

Newly licensed registered nurse. A registered nurse during their first 1 to 2 years of nursing practice (Brewer, Kovner, Greene, Tukov-Shuser, \& Djukic, 2012).

Preceptor. An experienced RN responsible for orienting the NLRN to the cultural and work demands of the work setting in which the NLRN is hired (Lee, Tzeng, Lin, \& Yeh, 2009).

Preceptor role effectiveness. A measure of the preceptor qualities with negative and positive characteristics to the NLRN orientation process (Lee et al., 2009)

Group cohesion. The ability of staff to work and communicate effectively (Tourangeau, Cranley, Laschinger, \& Pachis, 2010).

Intent to stay. "The stated probability of an individual staying within their position" (Cowden \& Cummings, 2012, 1653)

Job satisfaction. "The overall positive feeling towards one's work" (Cowden \& Cummings, 2012, p. 1653)

\section{Operational Definitions}

Preceptor role effectiveness. Preceptor role effectiveness was measured using the Preceptor Role Effectiveness Scale (PRES), a modification of the Clinical Instructor 
Characteristic Ranking Scale (CICRS) (Rauen, 1974). The total score of the PRES was calculated.

Group cohesion. Group cohesion was measured using the Group Cohesion scale. A total score for the Group Cohesion scale was calculated (Hinshaw \& Atwood, 1983).

Intent to stay. Intent to stay was measured using the Intent to Stay scale. A mean score for the Intent to Stay scale was calculated (Price, 2000).

Job satisfaction. Job satisfaction was measured using the Nurse Job Satisfaction scale (Hinshaw \& Atwood, 1983). A total score for the Nurse Job Satisfaction scale was calculated.

\section{Assumptions}

Assumptions for this research study included: 1) most hospital systems have new graduate residency programs, 2) the majority of these programs have required classes and coursework in association with having a preceptor on the floor in which the NLRN is hired, and

3) the newly licensed $\mathrm{RN}$ is able to provide direct patient care throughout the orientation and residency process. Other assumptions included: 4) the preceptor role effects the NLRN's transition to practice and 5) unit socialization impacts job satisfaction and intent to stay among NLRNs. The last assumptions were 6) there is a wide variety of nursing tenure to consist a unit and 7) the mix of staff experiences can impact the group cohesion of the group and the preceptors effectiveness.

\section{Limitations}

A limitation of this study was the cross-sectional design of data collection. This limits the ability to examine changes in the NLRN over the entire orientation period. A repeated measures design would allow the researcher insight into the possible changing opinions of the NLRN during the different phases of orientation and beyond. 
Another limitation was the inability to conduct this survey beyond one healthcare system. While the data collected from one system may effectively mimic results across the region and state, more wide-spread surveying would increase the generalizability of the findings to other populations.

A third limitation is the environment where the surveys were completed. The survey was presented during a residency class through an emailed solicitation with the survey link included. This method can lead to increased distraction and a loss of concentration by the participant. By utilizing this method, the convenience sampling may not representative of the entire NLRN population. This limited the generalizability of the results. 


\section{CHAPTER 2: REVIEW OF LITERATURE}

This chapter provides an overview of characteristic-specific literature pertinent to the area of study. The characteristics studied include: preceptor effectiveness, group cohesion, job satisfaction and intent to stay within the NLRN population.

\section{Preceptor Effectiveness}

The first factor of study was preceptor effectiveness and its involvement in nursing. According to Luhanga, Dickelson, and Mossey (2010) and supported through the literature preceptor effectiveness is a combination of factors that enhance the orienting experience specific to the preceptor. An effective preceptor ensures a quality orientation and creates an effective team member. Preceptor effectiveness is a large focus in nursing research, as it is an extensive process.

Luhanga, Dickleson, and Mossey (2010) aimed to explore and describe preceptor role support and development within a mid-sized Canadian hospital. A qualitative exploratory and descriptive design was used to gauge preceptors' feelings of effectiveness and development. The sample consisted of 22 nursing preceptors in a rural and northern Canadian hospital setting. Preceptors' nursing experience ranged from 4 to 32 years, with a range of 1 to 22 years of precepting experience. Luhanga et al. (2010) found four themes: accessible resources, role complexity, partners in precepting, and role development. Many preceptors expressed the need for more educational resources to better precept and evaluate new graduates. There was also a call to clearer role expectations while orienting. One of the last significant findings was the suggestion of preceptors to create a preceptor selection process. In conclusion, Luhanga et al. 
stated that it was clear that the surveyed preceptors were engaged in effective orientation of NLRNs and were actively seeking ways to better orient the next generation of nurses.

While Luhanga et al. (2010) focused on preceptors' perspective on effectiveness, Forneris and Peden-McAlpine (2009) took a more short-term approach to understand the impact of a preceptor on the novice nurse and their critical thinking skills during the first six months of orientation. Forneris and Peden-McAlpine used a qualitative instrumental case study design (Stake, 1995) to qualitatively survey six preceptor and preceptee groups during the first six months of preceptee practice. Interviews of preceptors occurred during months one and six. During the two preceptor interviews two themes emerged. The first theme was critical thinking as organizing and carrying out tasks. Forneris and Peden-McAlpine found that the main critical thinking struggle centered on the promptness and ability of the NLRN to complete tasks in a timely and effective manner. The second theme that emerged during the second round of preceptor interviews was the changes in NLRNs' critical thinking to more intentional and reflective as experience was obtained. Forneris and Peden-McAlpine surmised that during this time the team noticed the transformation of NLRNs from task oriented to bigger-picture and patient-focused. In conclusion, the results of Forneris and Peden-McAlpine's study highlighted the importance of preceptor awareness of the role of anxiety on critical thinking in every phase. In addition, Forneris and Peden-McAlpine expressed the resounding need of the preceptor to create supportive dialogue to help promote the growth of critical thinking skills within the preceptee.

As a change from solely the preceptors' viewpoint, Fox, Henderson, and Malko-Nyhan (2006) compared the preceptor and preceptee's opinions of the effectiveness of the preceptor role as a comparison. Newly licensed registered nurses who were assigned preceptors, as well as 
preceptors, were sent surveys at two time periods during orientation: 1) months two and three, and 2) months six through nine. The first data collection period had 33 respondents and the second data collection period had 17 respondents. Interestingly, in the first data collection period, preceptees felt that the preceptors were available for feedback and help consistently $(74.2 \%, 23 / 31)$ while the preceptors felt that they were inadequately available $(63.6 \%, 7 / 11)$. During the second data collection point, the preceptees felt their preceptors were less available (76.5\%, 13/17), while preceptors expressed increased ability to provide feedback and support (83.4\%). Fox et al. (2006) concluded that while perceptions of aid from both the preceptor and the preceptee may differ, the preceptee is being assisted adequately in the transition to the floor. Increased role awareness of the preceptor and preceptee may help settle perceived areas of incongruence to better aid in more supportive transitioning.

To approach an understanding of the more intimate impact of the preceptor and preceptee dynamic, Raines and Lynn (2009) explored the relationship of the preceptor and preceptee by describing the caring components of the preceptor's behavior. Raines and Lynn used a qualitative, retrospective review of self-reported preceptor stories following a preceptor training course. The sample consisted of 56 preceptor stories about the experience of precepting NLRNs during orientation. Raines and Lynn identified three themes: respect for others, mutual trust, and transformative relationships. Respect was listed as one of the most prevalent and important themes, occurring 34 or $63 \%$ of the time. The transformative relationship focused on the ability of the preceptee to transform in their role of practice. Raines and Lynn's findings clearly demonstrated the importance of the preceptor in creating a positive relationship in order to promote orientation effectiveness.

Understanding the entirety of a residency program, Spiva et al. (2013) conducted a 
qualitative study using grounded theory to describe and identify ways to enhance NLRNs' orientation experiences, shedding light specifically on the NLRNs' preceptor experience. The sample consisted of 21 NLRNs who had completed and participated in a formal residency program between October 2010 and February 2012. Several themes emerged related to the impact of the preceptor on the NLRN (Spiva et al., 2013). The first was that satisfactory or unsatisfactory preceptorships could either enhance orientation or act as a hindrance. Positive outcomes from satisfactory preceptorship as expressed by the NLRNs included: open and constructive communication and feedback and enhanced confidence in building independent practice. Negative outcomes from unsatisfactory preceptorship included: increased anxiety on the job, inconsistent feedback, inappropriate correction methods, and decreased supervision during needed instruction times. Spiva et al.'s study clearly expressed how pivotal effective preceptorships are on the orientation process of NLRNs. In addition, Spiva et al.'s findings stress the importance of matching the right NLRN with the right preceptor.

By evaluating a nationally instituted preceptor program, Haggerty, Holloway, and Wilson (2013) researched the process of nurse entry to practice programs and ways to fine-tune practices to aid in nurse retention through preceptor specific measures. The design of this study was based on the Fourth Generation Evaluation (Guba \& Lincoln, 1989) in longitudinal studies. The sample consisted of 1044 NLRNs that were entering practice in New Zealand between 2007 and 2009 and who were participating in the nurse entry to practice program (NETP). Overall, Haggerty et al. (2013) found that the NETP was a very effective preceptor orientation model. Unsurprisingly, Haggerty et al. also found that satisfaction changed when working conditions limited staff flexibility, such as short staffing and lack of consistent preceptors. In conclusion, Haggerty et al. stated that the culture of preceptor and new nurse support was vital in allowing 
the new nurse to successfully assimilate into quality patient care.

\section{Group Cohesion}

Group cohesion within the macro and micro systems of the inpatient setting is well understood; however, a closer understanding of the impact of group cohesion on the NLRN can aid in steering preceptorships and residency programs to best practice. As the cohesion of a group is vital for work-life, it is important to understand and constantly strive to enhance the group environment to be conducive to the new nurse.

Li, Early, Mahrer, Klaristenfeld, and Gold (2014) conducted a quantitative study to determine if positive group cohesion and organizational commitment can protect the new nurse from negative factors such as burnout and compassion fatigue, as examples. The convenience sample included 251 nurses participating in the residency process at a large children's hospital. Li et al. (2014) found that group cohesion played the strongest role in increasing compassion satisfaction $\left(R^{2}=0.16, F(2172)=16.678, p<0.001\right)$, reducing burnout $\left(R^{2}=0.22, F(1172)=\right.$ $46.920, p<0.001)$, and compassion fatigue $\left(R^{2}=0.42, F(2172)=61.748, p<0.001\right)$. Group cohesion was found to effectively protect from negative factors such as burnout, compassion fatigue, and increase compassion satisfaction. Li et al. also found that group cohesion had an inverse relationship with stress exposure, posttraumatic stress disorder (PTSD) symptoms, and negative outcomes. In conclusion, Li et al.'s study findings identified positive insights into potential retention strategies that can be created to keep quality nurses at the bedside.

Feng and Tsai (2012) chose a qualitative descriptive approach to understand group cohesion from the NLRN perspective and to explore the experience of new graduate nurses in their socialization into nursing practice. Seven baccalaureate prepared, first time nurses consented to take part in the interview process. Feng and Tsai gleaned three themes from the 
interview process: overwhelming chaos, learning by doing, and being an insider. In the first theme, NLRNs discussed how unprepared they felt entering the practice environment after graduation as well as their frustration and inability to cope independently in practice without relying on the preceptor and the group. The second theme, learning by doing, uncovered that most nurses felt that their knowledge from school did not necessarily cross over to their practice and that new knowledge was best gained through self-direction in independent practice among the group. In the last theme, being an insider, the nurses discussed the transition process that had to be undertaken in order to fit in with the staff. NLRNs shared their challenges about the transition process, but ultimately when the feeling of "being an insider" set in, the feelings of chaos became more controllable (Feng \& Tsai, 2012). The most difficult challenge expressed by NLRNs was the ability to balance professional values with organizational values. Feng and Tais concluded that if a common chord could be reached between the patient-centered focus of the nurse and the task-centered focus of the organization, the transition process for the NLRN could become easier.

Focusing beyond simple perception of group cohesion, Martin and Wilson (2011) conducted a qualitative, interpretive, phenomenological study focusing on how group cohesion affects the ease of orientation for the NLRN. The sample consisted of seven NLRNs participating in a residency program. Martin and Wilson unearthed two themes from the interviews: adapting to the culture of nursing and developing professional responsibilities. Martin and Wilson found that group cohesion played a large role in the area of adapting to the culture of nursing. Furthermore, it was evident in the research findings that the ability of the new nurse to have positive group cohesion with coworkers was a key in the ability of the new nurse to successfully adapt to the practice environment. In conclusion, Martin and Wilson stressed the 
importance of nurturing positive group interactions while promoting more floor-specific education during the beginning phases of orientation.

Similarly, Phillips, Kenny, Esterman, and Smith (2013) aimed to describe the factors needed from a new graduate's perspective for successful transition to practice. A secondary data analysis was conducted on pre-existing qualitative data from two samples of NLRNs transitioning into their roles (total sample 459 NLRNs). Phillips et al. found the following themes: matching skill sets, the beginning foundation, and a job well done. As the first theme, the NLRNs felt that their competency and skill set should be matched with patient assignments. The NLRNs expressed that the mismatch in levels caused great stress. The second theme, the beginning foundation discussed the transition of nursing experience from orientation to the beginnings of nursing practice. The last theme, a job well done, discusses the NLRN transition into more independent practice within the group and the sense of satisfaction of the NLRN independent practice ability. Through interpretations from the three themes, it was evident that the feeling of new graduates in how they were valued by the nursing profession as well as their acceptance into the work environment was crucial in successful transition (Phillips et al., 2013). Group cohesion of both the hospital and the nursing unit were essential for the new graduate to successfully complete orientation. The prominent area of focus was the fostering of an environment of collegial respect (Phillips, 2013)

As a more specific cultural measure, Malouf and West (2010) attempted to better understand how Australian NLRNs experienced their transitions into acute care practice settings. Using a qualitative constant comparison analysis, nine Australian NLRNs were interviewed three times during their first year of practice. Many of the first reactions of the NLRNs were in regards to anxiety surrounding staff interactions and the ability to assimilate into the team 
(Malouf \& West, 2010). Malouf and West found from the beginning of orientation that NLRNs valued group cohesion. Other themes from the interviews included the trepidation in not wanting to feel "stupid" and fitting in again (Malouf \& West, 2010). Malouf and West's findings are congruent with other researchers' findings (Feng \& Tsai, 2012; Martin \& Wilson, 2011; Phillips et al., 2013) in relationship to group cohesion and NLRNs; group cohesion has been found to be essential for a successful orientation as well as a successful retention and transition tool for nurses to promote competent and quality care.

Understanding the broad perspective of orientation in order to gauge the specific value of group cohesion, McKenna and Newton (2008) sought to determine how nurses developed their skills in the first 18 months of practice as well as identify areas that inhibited their knowledge development. The design consisted of a qualitative approach while using Colazzi's framework (Colazzi, 1978) for data analysis. The final sample comprised nine participants practicing in public and private healthcare systems in Australia. The participants were surveyed at three different time intervals during an 18-month period. McKenna and Newton found three themes: sense of belonging, independence, and moving on. A sense of belonging was vital for NLRNs from the beginning of orientation. The need for positive group cohesion was also seen in the theme of independence. Typically taking place between months $12-18$, the NLRN has fostered a sense of independence in care tasks, and yet the continued need to have a supportive staff environment in case of patient deterioration was evident from the NLRNs interviews. The third theme, moving on, was portrayed as the stage where NLRNs stopped feeling like an "outsider" and started feeling like a valid part of the team, enhancing the cohesion for the next set of NLRNs coming in by becoming an informal ally and educator. 


\section{Job Satisfaction}

There are innumerable factors that can enhance or detract from job satisfaction of nurses as studied by Halfer et al. (2008), Park et al. (2012), and Glynn et al. (2013), to name a few. Understanding job satisfaction characteristics specific to certain populations help to identify factors that promote job satisfaction of nurses. One population that is integral to sustained healthcare growth is that of the NLRN and therefore, understanding factors that promote the NLRN's job satisfaction is paramount.

Park, Yun, and Cho (2012) examined the job satisfaction of NLRNs. The purpose of the study was to compare new nurses' job satisfaction factors against other allied health professionals and other social help professions (such as social workers and teachers) in order to find job satisfaction factors specific to nursing. The samples included 622 female new graduates, 152 nurses, 68 allied hospital professionals, 110 social workers, and 292 elementary school teachers working as full-time employees with less than 2 years of experience within their fields. Park, Yun, and Cho found that when compared to two of the three groups (social workers and elementary school teachers) nurses were the least satisfied with all of their job characteristics $(O R=0.087, p<.001 ; O R=0.509, p=.007)$. Nurses only had comparable job satisfaction characteristics with other allied health professionals in the area of job security $(O R=2.082 ; 95 \%$ CI $[1.141,3.798] ; p=.017)$, otherwise in all other characteristics new graduate nurses were the least satisfied. The most dissatisfying factor of nurses was hours worked. Conclusively, Park, Yun, and Cho emphasized that the factors, which contributed to the highest dissatisfaction of nurses, such as hours worked and stressed involved on the job, should be focused on being alleviated. Without attempting to resolve these issues new nurses are at increased risk for job dissatisfaction and turnover. 
Laschinger (2012) strived to uncover factors of job satisfaction and turnover intentions for NLRNs within an Ontario setting. Laschinger used a cross-sectional data analysis of mailed survey results from 342 NLRNs practicing within their first two years of practice. Laschinger found that the factor that most positively correlated with job satisfaction was global empowerment ( $r=0.81$ in year $1, r=0.78$ in year 2$)$, or the ability to own independent practice within a team. The factor that most inversely correlated with job satisfaction was work-related bullying in year one $(r=-0.63)$. Empowerment, work engagement and burnout were important significant predictors of job satisfaction (Laschinger, 2012). While many factors addressing job satisfaction were surveyed, Laschinger discovered that easily modified workplace factors played a key role in new graduate job satisfaction.

Giallonardo, Wong, and Iwasiw (2010) offered more information regarding NLRN specific satisfaction factors. The purpose of Giallonardo et al.'s (2010) study was to examine the connectedness of the factors of preceptor leadership, work engagement, and job satisfaction. Giallonard et al. conducted a non-experimental, predictive survey including 170 NLRNs with less than 3 years' experience who worked in the in-patient setting. The surveyed nurses reported that work engagement $(\beta=0.34, t=4.80, p<0.01)$ and preceptor leadership $(\beta=0.22, t=3.02$, $p<0.01)$ were both independent predictors of job satisfaction (Giallonardo et al., 2010).

Giallonardo et al. concluded that preceptorship, which then transitions to the authentic leadership characteristic following orientation and engagement predicted the largest portions of NLRNs' satisfaction.

By adding an additional filter specific to NLRN satisfaction, Glynn, Silva, Weston, and Norwood (2013) delved into the relationship of a new graduate nurse internship program within the Emergency Department. A qualitative design was utilized in order to understand the 
experiences of the NLRN within a structured internship program. Three main benefits of the internship emerged. The first benefit identified was the ability of the nurses to learn new skills in the specialty area. The second was the ability of the nurses in the internship in becoming more proficient in competent independent practice. The last benefit was the assistance with role transition. Glynn et al. (2013) concluded that a structured internship or residency can positively contribute to NLRN job satisfaction by empowering the nurse in knowledge, skill level, and ability of independent practice.

Halfer, Graf, and Sullivan (2008) conducted a descriptive quantitative study to explore NLRNs' job satisfaction specific to the pediatric nurse. The sample $(n=234)$ consisted of two cohorts of NLRNs, one before and one after the implementation of an internship program. Halfer et al. (2008) found that voluntary turnover dropped from $20 \%$ before to $12 \%$ during the first year after the internship program was initiated. In addition, job satisfaction was statistically significantly higher in the post-internship group than the pre-internship group $(p=0.046)$. In

summary, Halfer et al. determined that that the mentoring program aided job satisfaction, thereby decreasing turnover rates over a 2 year period.

\section{Intent to Stay}

Lee, Tzeng, Lin, and Yeh, (2009) discussed the role of a formal preceptorship process on the retention and cost benefit of the NLRN. Lee et al. used a quasi-experimental design to study these effects in a large teaching facility in Taiwan. Thirty four of the 123 NLRNs participated in the experimental program which resulted in a $46.5 \%$ reduction in one year (Lee et al., 2009). Turnover cost saved was $\$ 186,102$ during the six-month study period. In the majority of statistics, NLRNs reported more comfort with ease of transition, patients were more satisfied, and the remainder of staff expressed increased work satisfaction. In conclusion, the internship 
has been proven effective in reducing turnover and improving patient outcomes, therefore impacting NLRNs' intent to stay (Lee et al., 2009).

As a positive impetus for NLRN residency formation, Brewer, Kovner, Greene, TukovShuser, and Djukic, (2012) explored the culture of nursing prior to NLRN residency program formation. Brewer and colleagues highlighted the need for the NLRN residency creation by surveying the NLRN culture, particularly surrounding the NLRN experience and challenges in the workplace. With 1653 respondents, some key predictors were brought to light. In this sample $15 \%$ of respondents left their first nursing position within the first year of employment, costing around \$728 million in turnover costs (Brewer et al., 2012). Twenty-six percent of nurses left within their first two years. Out of this data only $24 \%$ had a formal residency program within their first year. Brewer et al. (2012) concluded that the two key characteristics that can positively sway turnover intentions are improved nursing satisfaction and enhancement of nursing's' organizational commitment.

Trepanier, Early, Ulrich, and Cherry (2012) provided another justification for the NLRN program through secondary data analysis compiled through multiple health resources in the southwest United States (US). Fifteen healthcare organizations were electronically surveyed for individual characteristics, contract labor usage, and turnover of the NLRN residency program. Turnover statistics were collected 12 months prior to residency, and 12 to 24 months after the residency. Trepanier et al. (2012) found that 255 NLRNs left prior to residency implementation, as opposed to 39 NLRNs post residency implementation ( $36.08 \%$ to $6.41 \%, p<0.05)$. Accompanying the drop in turnover, there was also a reduction in contract labor usage from $\$ 19,099$ to $\$ 5,490$ per average daily census $(p<0.05)$. Alleviating turnover at this rate indicates a cost savings of a potential $\$ 33.6$ million between the fifteen hospitals. Through Trepanier et al. 
study's findings, it was evident that the new graduate residency program offered effective cost savings in reducing NLRN turnover and intentions to stay.

Kovner, Brewer, Greene, and Fairchild (2009) explored the newly licensed registered nurses journey into the nursing career field and their intent to stay. All new nurses within metropolis areas in a 34 state region were mailed surveys, with 3380 participants who met the criteria. Similar to the previous study discussed from Brewer (2012), those married and with children were less likely to have intentions to leave. Mandatory overtime $(p=0.002$, coefficient $=0.296)$ and higher patient loads $(p=0.014$, coefficient $=-0.043)$, along with a variety of home factors, negatively impact NLRN intent to stay. Kovner et al. (2009) concluded that new nurses' intent to stay is a complicated and multivariable decision. Understanding stressors that negatively impact that decision and attempting to alleviate them should be a national initiative utilized to reduce turnover intentions.

Lavoie-Tremblay, O'Brien-Pallas, Gelinas, Desforges, and Marchionni (2008) conducted a correlational, descriptive study to investigate how psychological work factors affect intent to leave among NLRNs. While intent to leave is a different approach to study retention than intent to stay, it is still a valid indicator of nursing retention within a system. All English speaking Canadian nurses who were under the age of 24 and had attained their nursing licensure by August 1, 2005 were surveyed, leaving a sample size of 309 nurses. Lavoie-Tremblay et al. (2008) identified factors enhancing the intent to quit included lack of challenges, career opportunities, and difficult working conditions. Significant psychological factors leading to intent to quit the nurses' current position were effort and reward imbalance $\left(X^{2}=14.561, p<\right.$ $0.001)$ and lack of social support $\left(X^{2}=29.362, p<0.001\right)$. Factors that characterized the nurses' intent to quit nursing that were significant included high psychological demand $\left(X^{2}=6.100, p<\right.$ 
$0.05)$, effort and reward imbalance $\left(X^{2}=11.197, p<0.01\right)$ and elevated job strain $\left(X^{2}=4.771, p\right.$ $<0.05)$. Lavoie-Tremblay et al. summarized that the imbalance between effort and reward was a key factor between nurses' intent to leave both their current positions as well as their careers. If this factor alone can be better understood and better controlled, nurses can be more satisfied and comfortable in their caregiving roles.

Beecroft, Dorey, and Wenten, (2008) set to better understand intent to stay with three specific variables: individual, work environment, and organizational. A prospective survey design was utilized with a sample of 889 new nurses who completed the same residency program from 1999 to 2006. The surveys were completed as part of an exit survey from their first year residency programs. Individual characteristics $(O R=0.99$ yes and $O R=1.02$ no, $p=0.502)$ played the highest factor in turnover intent followed by organization fit $(O R=0.94$ yes and $O R=$ 0.97 no, $p<0.001)$ and then by work environment $(O R=0.89$ yes and $O R=0.92$ no, $p<0.001)$. The individual characteristics that played the largest factor in intent to leave came from those who utilize avoidance and escape as ways of coping $(O R=1.02$ and $\mathrm{p}<0.001)$. Beecroft et al.'s (2008) findings clearly links personal job satisfaction to intent to stay. The second most important factor was organizational commitment. Beecroft et al. concluded that the key to keeping a NLRN is to ensure that they are happy in their positions and they are happy with the organization in which they are employed.

\section{Summary}

The variables of preceptor effectiveness, group cohesion, job satisfaction, and intent to stay are all closely related in the NLRN perception of the orientation process. While variables such as age and marital status can alter the connectedness of these four variables (Brewer et al., 2012), it is important to consistently understand how altering one variable can affect the others. 
Matching the right preceptors, who have characteristics such as caring and a willingness to teach, (Fox et al., 2006) with the right preceptees, who are provided an essential sense of belonging (McKenna et al., 2008) is vital in in order to maintain the right satisfaction (Giallanardo et al., 2010) and the right intent to stay (Lee et al., 2009). While matching the right preceptees and preceptors is important, the literature is also clear on the consequences of failing to meet these demands can be detrimental to the floor, nursing satisfaction, and nursing retention. Factors include turnover, decreased NLRN satisfaction, decreased staff satisfaction and increased patient safety risks (Brewer et al., 2012). 


\section{CHAPTER 3: METHODS}

This chapter reviews the methodology used in the study of NLRNs' experiences. Areas discussed in the methodology section include the research design, setting, population and sample, as well as the procedures for data collections. Additional areas discussed include the instruments to be used, threats to validity, data analysis, protection of human subjects and data security.

\section{Research Design}

A quantitative, cross-sectional, descriptive design was used. This research design was appropriate due to the focus being multi-factorial during one survey point for data collection. The variables of focus during the survey point were preceptor role effectiveness, group cohesion, job satisfaction, and intent to stay within the NLRN orientation process. The research was designed to understand the variables independently and relationally within one survey point. The research questions guiding the study were:

1. What were the perceived levels of preceptor role effectiveness, group cohesion, job satisfaction, and intent to stay for NLRNs?

2. What were the relationships between preceptor role effectiveness, group cohesion, job satisfaction, and intent to stay among NLRNs?

\section{Setting}

The setting was a regional, multi-hospital, community healthcare system. Within this healthcare system is a NLRN residency program that all NLRNs are responsible for completing during the first year of practice following nursing program graduation. The required monthly 
residency program classes take place out of the inpatient setting at an educational center.

\section{Population and Sample}

The population consisted of NLRNs during their first year of employment at a local healthcare system. The potential recruitment was approximately 160 NLRNs. A convenience sampling method was used. Inclusion criteria included: 1) nurses in their first year of practice, 2) enrolled in a residency program, 3) who practiced within the hospital setting, 4) speak and read English at an eighth grade level or higher, and 5) 18 years of age or older. The population was appropriate to study as it allowed the researcher to capture the most current experience of NLRNs instead of retrospectively, which prevented the clouding of participants' opinions and deterioration of memory recollection. Through a power analysis with a power of .80, an alpha of .05 , and an effect size of 0.30, 84 NLRNs were needed for the sample (Faul, Erdfelder, Buchner, \& Lang, 2009).

\section{Procedures for Data Collection}

Two methods were planned for data collection. First, participants were recruited by attending monthly residency classes. Permission was obtained from the residency program manager to attend the classes for recruitment (Appendix A). The data was collected through an online survey process using Survey Monkey. The researcher provided information to the participants about the research study and provided the link to the Survey Monkey questionnaire.

A scripted email (Appendix B) was sent out by the NLRN program manager to notify NLRNs in other cohorts not attending the class about the research study the day of residency class. An explanation of the research study, information about the researcher, and the survey link was included. Two weeks later, a second email was sent to the NLRNs as a follow up reminder about the study. 


\section{Instruments}

Four scales were included in the survey as well as a general demographic scale (Appendix C). The nursing specific scales were: Preceptor Role Effectiveness Scale (PRES) (Rauen, 1974) (Appendix D), Group Cohesion Scale (GCS) (Hinshaw \& Atwood, 1983) (Appendix E), Nurse Job Satisfaction Scale (NJS) (Hinshaw \& Atwood, 1983) (Appendix F), and the Intent to Stay Scale (ITS) (Kim, Price, Mueller, \& Watson, 1996) (Appendix G). The demographic scale included factors such as: age, gender, race, months of practice, employment area, shift type, and first healthcare position.

Clinical instructor ranking scale. The PRES (Appendix D) was a modification of the Clinical Instructor Ranking Scale and was used to measure the preceptor role effectiveness during the orientation experience (Rauen, 1974). Permission was obtained by the author to use and revise the scale to assess preceptors' role effectiveness (Appendix H). Content validity was established by a group of 25 nursing educators by reviewing the literature for characteristics of effective clinical instructors. Items were retrained meeting $80 \%$ or greater agreement by the content experts.

Test-retest reliability was established in a group of 50 nursing students during two survey points. A Spearman-Brown (S-B) prophecy formula yielded a .75 reliability coefficient (Rauen, 1974).

The instrument consisted of 18 items and is scored on a 4-point Likert format from 1 (strongly disagree) to 4 (strongly agree). NLRNs were asked to rate their preceptors' role effectiveness by selecting the appropriate response to each item. A total score was calculated by summing all responses to the items. The possible score range was from 18 to 72 with higher scores indicating higher preceptor role effectiveness. 
Group cohesion scale. The GCS (Hinshaw \& Atwood, 1983) (Appendix E) was created as an abbreviated version of the Interpersonal Judgment Scale created by Bryne 1961. Construct validity was established by conducting a principle factor analysis. All six items loaded on one factor with coefficients ranging from .49 to .81 . The one factor explained $52.9 \%$ of the variance in group cohesion. Internal consistency reliability was estimated with a Cronbach's coefficient alpha of 0.81 .

The response format was based on a 7-point Likert scale ranging from 1 (dislike it vary much, very much below average) to 7 (like it very much, very much above average). A total score was calculated by summing the item responses with possible scores ranging from 6 to 42 , with higher scores indicating a higher level of group cohesion. Permission was obtained from the authors to use the scale (Appendix I).

Nurse job satisfaction scale. The NJS measured professional nurse satisfaction (Hinshaw \& Atwood, 1983). The instrument consists of 23-items which were answered on a 5point Likert scale from strongly disagree (1) to strongly agree (5).

Construct validity was established using a factor analysis approach. Items loaded on three factors with factor coefficients of .45 or higher. The three factors were titled, enjoyment, quality of care, and time to do one's job. The three factors explained $53.8 \%$ of professional nurse job satisfaction (Hinshaw \& Atwood, 1983).

Cronbach's alpha coefficients for internal consistency reliability ranged from 0.76 for “time to do one's job," 0.85 for “enjoyment," and 0.77 for "quality of care.” Overall internal consistency reliability was 0.88 . The maximum obtainable score was 115 . Higher scores indicated higher job satisfaction (Hinshaw \& Atwood, 1983). Permission was obtained from the authors to use the scale (Appendix J). 
Intent to stay scale. The ITS was developed by Kim, Price, Mueller, \& Watson (1996) to more precisely measure the intention of staff in their willingness to stay at their place of employment. The instrument was originally used in surveying physicians within a military hospital setting. The scale consisted of four items with two positively worded items and two negatively worded items. The items focused on participants' plans and desires of leaving or staying with their present employer. Cronbach's alpha coefficient for internal consistency reliability was reported as .85 (Kim, Price, Mueller, \& Watson, 1996). The instrument was in the public domain (Price, 2000).

A 5-point Likert response format was used ranging from 1 (strongly disagree) to 5 (strongly agree). A mean score was obtained by averaging responses to the four items. Reverse scoring was conducted on the two negatively stated items prior to calculating the total mean score. Higher mean scores indicated higher intent to stay on the job.

\section{Threats to Validity}

There were three primary threats to the validity of this study. The first threat was the actual data collection method in itself. The convenience sampling was conducted at a single survey point. Since the survey point is only one period within the orientation process (survey will occur sometime in the first year of practice), there was a threat of skewed opinion in the participant since the participants have not completed the full orientation process. Several groups, at differing levels of orientation and residency were surveyed. Without the total scope of the orientation process being completed, the participant must give their most recent impression of the factors studied.

The second threat was that the surveys are only completed within one healthcare system. By casting a wide net in surveying several hospitals within one system some of the areas of 
practice threats were minimalized. Despite the variety in area of practice, there was still a threat within the same system, as broad policy and procedure practices are not unified, skewing some practices.

The third threat was the type of healthcare system studied. The setting was within a community hospital. This type of system can skew some of the research and education principles that affected the NLRN orientation experience. Other types of healthcare systems such as academic healthcare systems may generate different results.

Control of the threats are built within the research design. The first threat was controlled by sampling NLRNs in different phases of the orientation process. This indicated that a broad understanding of orientation can be gained in surveys throughout the first year of practice. Another control was in ensuring that survey participation in no way impacted the orientation participation. This allowed the participants to answer the survey questions honestly. The other threats could not directly be controlled in this survey collection point; however, future studies may offer more comparisons across healthcare systems as well as different types of healthcare systems.

\section{Data Analysis}

Descriptive and inferential statistics were analyzed using SPSS for Windows Release 21.0. A pre-analysis data screening was conducted to ensure the accuracy of data entry. Descriptive statistics (frequencies, percentages, means, and standard deviations) was performed to describe the sample characteristics and NLRNs' perceived preceptor role effectiveness, group cohesion, job satisfaction, and intent to stay. Correlational analyses were conducted to examine the relationships between and among NLRNs' perceived preceptor role effectiveness, group cohesion, job satisfaction, and intent to stay. Cronbach's alpha reliability coefficients was 
calculated to determine internal consistency reliability of the PRES, GCS, NJS, and ITS. An alpha value of $\leq 0.05$ was considered statistically significant.

Protection of Human Subjects

Approval of the research study was obtained from the healthcare system's Nursing Research Committee (Appendix K) and from Kennesaw State University Institutional Review Board (IRB) (Appendix L). An informed consent (Appendix M) was presented to the NLRNs to explain the purpose of the research study. NLRNs were advised that they would complete a demographic survey and four other surveys. NLRNs were informed that completion of the surveys will take appropriately 15 to 20 minutes to complete. Consent was implied by completion of the surveys. NLRNs were informed that all data collected for the study will be kept in a confidential manner.

\section{Data Security}

Data remained secured through the entirety of the research process. Participant confidentiality was maintained by not collecting any identifying information or Internet Protocol (IP) addresses. Access to the Survey Monkey data was password protected. Data was downloaded to a jump drive device for data analysis. The jump drive device was stored in a locked file cabinet when not in use. Data was shared with the researcher's faculty and those directly involved in data analysis. All data related to the research study will be stored for three years at the healthcare system's Center for Nursing Excellence department and then destroyed. 


\section{CHAPTER 4: RESULTS}

This chapter formulates a concise summary of the data and data analysis. This chapter presents the data analysis plan, the sample characteristics, and the data analysis results. Data analysis was conducted to answer the following questions: 1) What were the perceived levels of preceptor role effectiveness, group cohesion, job satisfaction, and intent to stay for NLRNs? 2) What were the relationships between preceptor role effectiveness, group cohesion, job satisfaction, and intent to stay among NLRNs?

\section{Data Analysis}

Descriptive and inferential statistics were analyzed using SPSS for Windows Release 21.0. A pre-analysis data screening was conducted to ensure the accuracy of data entry. Descriptive statistics (frequencies, percentages, means, and standard deviations) were performed to describe the sample characteristics and NLRNs' perceived preceptor role effectiveness, group cohesion, job satisfaction, and intent to stay. Correlational analyses were conducted to examine the relationships between and among NLRNs' perceived preceptor role effectiveness, group cohesion, job satisfaction, and intent to stay. Cronbach's alpha reliability coefficients were calculated to determine internal consistency reliability of the Preceptor Role Effectiveness Scale (PRES), Group Cohesion Scale (GCS), Nursing Jobs Satisfaction Scale (JSS), and Intent to Stay Scale (ITS). An alpha value of $\leq 0.05$ was considered statistically significant.

\section{Participation Rate}

By email solicitation, 210 NLRNs were recruited. Of the population sampled, 88 participants responded to the survey. Out of the 88 newly licensed RNs who participated, four 
surveys were omitted due to incompleteness. A total of 84 questionnaires were used for data analysis, resulting in a usable return rate of $40 \%$.

\section{Sample Characteristics}

The majority of newly licensed RNs were female $(n=78,92.9 \%)$ and Caucasian $(n=56$, $66.7 \%)$. The mean age was 28.03 years $(S D=6.94)$ with a range of 21 to 50 years. The participants were licensed as RNs for an average of 7.43 months $(S D=4.88)$ with a range from one to 18 months. The majority of NLRNs practiced in acute care $(n=45,53.6 \%)$ followed by critical care $(n=19,22.6 \%)$, emergency department $(n=11,13.1 \%)$, women's services $(n=6$, $7.1 \%)$, and other $(n=3,3.6 \%)$. Fifty-six percent $(n=47)$ of NLRNs worked night shift. All of the participants $(n=84,100 \%)$ indicated that they were offered a one-on-one preceptorship with an experienced nurse. Over half $(n=52,61.9 \%)$ worked in a healthcare setting prior to their first nursing position. 
Table 1

Demographic Characteristics $(N=84)$.

Characteristics

Age

Months Licensed

\begin{tabular}{cc}
$M$ & $S D$ \\
\hline 28.03 & 6.94 \\
7.43 & 4.88
\end{tabular}

Gender

Male

Female

Missing

N $\%$

5

6.0

$\begin{array}{ll}78 & 92.9\end{array}$

$1 \quad 1.2$

Race

Asian/Pacific Islander

6

7.1

Black/African American

17.9

Hispanic/Latino

15

3.6

White/Caucasian

3

66.7

Other

56

3.6

Missing

3

$1 \quad 1.2$

Practice Area

Acute Care

45

53.6

Critical Care

19

Women's Services

6

22.6

Emergency Department

11

7.1

Other

3

13.1

3.6

Shift

7A - 7P

29

34.5

$7 \mathrm{P}-7 \mathrm{~A}$

47

56.0

Other

7

Missing

1

8.3

1.2

Preceptorship

No

0

0.0

Yes

84

100

Pre-RN License Experience

No

32

38.1

Yes

52

61.9 


\section{Instrument Reliability}

Internal consistency reliability was assessed for the Preceptor Role Effectiveness scale (PRES), Group Cohesion scale (GCS), Job Satisfaction scale (JSS), and Intent to Stay scale (ITS) by calculating Cronbach's alpha reliability coefficients. The Cronbach's alpha reliability coefficient for the Preceptor Role Effectiveness scale was 0.97 and for the Group Cohesion scale 0.92. The Job Satisfaction scale Cronbach's alpha reliability coefficient was 0.92 with the following subscales Cronbach's alpha reliability coefficients: Quality of Care (0.81), Enjoyment (0.91), and Time to Do Job (0.78). The Cronbach's alpha reliability coefficient for the Intent to Stay scale was 0.92 . The results of Cronbach's alpha reliability coefficients indicate that all four scales and the Job Satisfaction subscales demonstrate moderate to high levels of internal consistency reliability.

\section{Research Questions}

Research question one. Research question one examined the perceived levels of preceptor role effectiveness, group cohesion, job satisfaction, and intent to stay for NLRNs. The potential score range for the PRES was 18 to 72 (Table 2). NLRNs scores ranged from 18 to 72 with a mean of $65.37(S D=9.38)$, indicating a high perceived level of preceptor role effectiveness.

The potential score range for the GCS was 6 to 42 . NLRNs scores ranged from 15 to 42 with a mean of $32.80(S D=6.67)$, indicating a high perceived level of group cohesion.

The potential score range for the total JSS was 23 to 115 . The potential score ranges for the subscales were as follows: 1) quality of care subscale 7 to 35,2 ) enjoyment subscale 10 to 50, and 3) time to do job subscale 5 to25. NLRNs scores for the total JSS ranged between 36 to 105 , with a mean score of $80.62(S D=13.91)$, indicating a high perceived level of job 
satisfaction. The quality of care subscale scores ranged from 12 to 35 with a mean of 24.84 ( $S D$ $=4.55)$. The enjoyment subscale scores ranged from 14 to 48 with a mean of $36.77(S D=7.37)$. The time to do job subscale scores ranged from 6 - 24 with a mean of $15.25(S D=3.90)$. All of the subscales indicated high perceived levels of quality of care, enjoyment, and time to do job.

The potential score range for the ITS was 1 to 5 . NLRNs scores ranged from 1 to 5 with a mean of $3.30(S D=1.10)$, indicating a moderate perceived level of intent to stay. Table 2

Score Ranges, Means, and Standard Deviations for the PRES, GCS, JSS, and ITS $(N=84)$.

\begin{tabular}{|c|c|c|c|c|c|}
\hline & Instrument & $\begin{array}{c}\text { Potential Score } \\
\text { Ranges } \\
\end{array}$ & $\begin{array}{c}\text { Participants' Score } \\
\text { Ranges }\end{array}$ & $M$ & $S D$ \\
\hline PRES & & $18-72$ & $18-72$ & 65.37 & 9.38 \\
\hline GCS & & $6-42$ & $15-42$ & 32.80 & 6.67 \\
\hline JSS & & $23-115$ & $36-105$ & 80.62 & 13.91 \\
\hline & Quality of Care & $7-35$ & $12-35$ & 24.84 & 4.55 \\
\hline & Enjoyment & $10-50$ & $14-48$ & 36.77 & 7.37 \\
\hline & Time to Do Job & $5-25$ & $6-24$ & 15.25 & 3.90 \\
\hline ITS & & $1-5$ & $1-5$ & 3.30 & 1.10 \\
\hline
\end{tabular}

Research question two. Research question two examined the relationships between preceptor role effectiveness, group cohesion, job satisfaction, and intent to stay among NLRNs. Statistically significant relationships were found between preceptor role effectiveness and job satisfaction, $r(84)=0.277, p=0.012$; intent to stay, $r(84)=0.262, p=0.017$; and job enjoyment subscale, $r(84)=0.287, p=0.009$. Preceptor role effectiveness had low moderate, positive relationships with job satisfaction, intent to stay and job enjoyment subscale. No statistically significant relationships were found between preceptor role effectiveness and group cohesion, $r(84)=0.140, p=0.208$, quality of care subscale, $r(84)=0.218, p=0.51$, and time to do job subscale, $r(84)=0.145, p=0.197$.

Statistically significant relationships were found between group cohesion and job 
satisfaction, $r(84)=0.569, p<0.01$; intent to stay, $r(84)=0.553, p<0.01$; quality of care subscale, $r(84)=0.457, p<0.01$; job enjoyment subscale, $r(84)=0.515, p<0.01$; and time to do job subscale, $r(84)=0.415, p<0.01$. Group cohesion has moderately positive relationships with job satisfaction, intent to stay, quality of care, job enjoyment, and time to do job.

Statistically significant relationships were found between job satisfaction and intent to stay, $r(84)=0.755, p<0.01$; quality of care subscale, $r(84)=0.803, p<0.01$; job enjoyment subscale, $r(84)=0.881, p<0.01$; and time to do job subscale, $r(84)=0.784, p<0.01$. Job satisfaction has strong positive relationships with intent to stay, quality of care, job enjoyment, and time to do job.

Statistically significant relationships were found between intent to stay and quality of care subscale, $r(84)=0.441, p<0.01$; job enjoyment subscale, $r(84)=0.771, p<0.01$; and time to do job subscale, $r(84)=0.576, p<0.01$. Intent to stay has strong positive relationships with quality of care, job enjoyment, and time to do job. 
Table 3

Correlation Matrix between PRES, GCS, JSS, and ITS $(N=84)$.

\begin{tabular}{|c|c|c|c|c|c|c|c|c|}
\hline & & PRES & GCS & JSS & $\begin{array}{l}\text { Quality } \\
\text { of Care } \\
\text { Subscale }\end{array}$ & $\begin{array}{c}\text { Enjoy } \\
\text { ment } \\
\text { Subscale }\end{array}$ & $\begin{array}{l}\text { Time to } \\
\text { Do Job } \\
\text { Subscale }\end{array}$ & ITS \\
\hline PRES & & 1 & .140 & $.277 *$ & .218 & $.287 * *$ & .145 & $.262 *$ \\
\hline GCS & & & 1 & $.569 *$ & $.457 * *$ & $.515 * *$ & $.415 * *$ & $.553^{*}$ \\
\hline JSS & & & & $*$ & $.803^{* *}$ & $.881 * *$ & $.784 * *$ & $*$ \\
\hline & Quality of Care & & & 1 & 1 & $.493 * *$ & $.652 * *$ & $.755^{*}$ \\
\hline & Enjoyment & & & & & 1 & $.492 * *$ & $*$ \\
\hline & Time to Do Job & & & & & & 1 & $.441 *$ \\
\hline \multirow[t]{5}{*}{ ITS } & & & & & & & & $*$ \\
\hline & & & & & & & & $.771 *$ \\
\hline & & & & & & & & * \\
\hline & & & & & & & & $.576^{*}$ \\
\hline & & & & & & & & 1 \\
\hline
\end{tabular}




\section{CHAPTER 5: DICUSSION}

This chapter discusses the implications of the research findings to the nursing profession. Limitations to the study will be discussed along with nursing practice, education, and future research implications. By analyzing the results further and synthesizing these results with other research, patterns of NLRN culture and future NLRN needs can be anticipated. By comparing the results of the research questions with current literature, a better analysis of the research findings can be seen.

In this study, statistically significant relationships were found between preceptor role effectiveness, job satisfaction, intent to stay, and job enjoyment. Preceptor role effectiveness had moderately, positive relationships with job satisfaction, intent to stay and job enjoyment among NLRNs. Findings pertaining to preceptor role effectiveness have been reported by other researchers (Forneris \& Peden-McAlpine, 2009; Giallonardo et al., 2010; Glynn et al., 2013; Haggerty et al., 2013; Laschinger, 2012; Luhanga, Dickson, \& Mossey, 2010; Haggerty, Holloway, \& Wilson, 2013; Raines \& Lynn, 2009; Spiva et al. 2013). An effective preceptor ensures a quality orientation and may help to socialize a NLRN to become a productive team member (Luhanga, Dickelson, \& Mossey, 2010). In addition, a critical role for preceptors is to create supportive dialogue that promotes the growth of critical thinking skills within the NLRN (Forneris \& Peden-McAlpine, 2009). Effective preceptors are instrumental in building respect and mutual trust in transformative relationships with NLRNs to promote a supportive transitional environment to nursing practice (Raines \& Lynn, 2009). One NLRN in this study articulated this viewpoint, "Love my preceptor. She helps me to be independent and asks questions that I don't 
always already know the answer to which is a good thing. The questions she asks gives me a basisfor the types of questions I should be asking myself."

Significant predictors of NLRNs' job satisfaction have been identified as work engagement and preceptor leadership (Giallonardo et al., 2010). Laschinger (2012) asserts that NLRNs who felt empowered and had the ability to practice independently as a team member demonstrate higher levels of job satisfaction. Furthermore, job satisfaction can be negatively impacted by work-related bullying during the first year (Laschinger, 2012).

Positive outcomes from satisfactory preceptorships have been found to include open and constructive communication and feedback, and enhanced confidence in building independent practice (Spiva et al., 2013). In contrast, negative outcomes from unsatisfactory preceptorships can result in increased anxiety on the job, inconsistent feedback, inappropriate correction methods, and decreased supervision during needed instruction times (Spiva et al., 2013). One NLRN shared this viewpoint of her preceptor, "The preceptor is what makes the job, without such an amazing preceptor I would not have the same outlook on this facility or my job. I love what I do and where I am at because she made learning easy and I feel comfortable with the people I work with." An effective preceptor is key to the successful assimilation of the NLRN into the role of a professional nurse (Haggerty et al., 2013).

Internships and nurse residency programs have been shown to be beneficial in increasing the degree of job satisfaction and retention of NLRNs (Glynn et al., 2013). NLRNs participating in an internship or nurse residency program reported higher levels of job satisfaction due to their ability to learn new skills, ability to become more proficient in competent independent practice, and an easier transition into nursing practice (Glynn et al., 2013).

Another important finding in this study was the statistically significant relationships 
between group cohesion and job satisfaction, intent to stay, and NLRNs' perceived levels of quality of care, job enjoyment and time to do job. Group cohesion had moderately, positive relationships with job satisfaction, intent to stay, and perceived levels of quality of care, job enjoyment, and time to do job among NLRNs. Group cohesion findings in this study have been supported by similar research findings (Feng \& Tsai, 2012; Li et al., 2010; Malouf \& Weset, 2010; Martin \& Wilson, 2011; McKenna \& Newton, 2008; Phillips et al., 2013). Group cohesion has been identified as an important factor in the intent to stay of NLRNs during the first year of transition (Li et al., 2014). As the cohesion of a group is vital for work-life, understanding and constantly striving to enhance the group environment to be conducive to the new nurse is a critical role of nursing administrators. NLRNs' fear of "fitting in" can affect their perceptions of group cohesion (Malouf \& West, 2010). A sense of belonging and positive feelings of "fitting in" or "being an insider" protects the NLRN from negative factors such as burnout, stress, and anxiety (Feng \& Tsai, 2012; Li et al., 2014; McKenna \& West, 2008).

A supportive work environment can assist the NLRN in overcoming feelings of frustration and an inability to cope independently in practice during the initial transition period to practice. Martin and Wilson (2011) stressed the importance that group cohesion plays in the area of the NLRN adapting to the culture of nursing. The ability of the NLRN to have supportive, positive relationships with coworkers is key in the ability of the NLRN to successfully adapt to the practice environment. A NLRN's feeling of being valued by their coworkers and their acceptance into the work environment is crucial in a successful transition, job satisfaction, and intent to stay (Philips et al., 2013). 


\section{Limitations}

A limitation of this study was the cross-sectional design of data collection. This limits the ability to examine changes in the NLRN over the entire orientation period. A repeated measures design would allow the researcher insight into the possible changing opinions of the NLRN during the different phases of orientation and beyond.

Another limitation was the inability to conduct this survey beyond one healthcare system. While the data collected from one system may effectively mimic results across the region and state, more wide-spread surveying would increase the generalizability of the findings to other populations.

A third limitation is the environment where the surveys were completed. The survey was presented during a residency class through an emailed solicitation with the survey link included. This method can lead to increased distraction and a loss of concentration by the participant. By utilizing this method, the convenience sampling may not representative of the entire NLRN population. This limited the generalizability of the results.

\section{Implications}

The research findings of this study reveal an updated perspective on implications to benefit the NLRN. By uncovering a small area of NLRN experiences, greater implications to enhance areas of practice, educational opportunities, and future research can be addressed.

Nursing practice. There are a plethora of nursing practice implications as evidenced by the research findings. The first is a re-emphasis of an effective preceptor. As seen by the strong positive relationship of an effective preceptorship with group cohesion, intent to stay, and job satisfaction, further training and maintaining an effective preceptor pool is of upmost importance. Matching the right preceptor to right preceptee is imperative in developing effective relationships 
to effectively guide and support the NLRN during the transition phase.

Another nursing implication is the importance of a healthy work environment in the transition of the NLRN into practice. An important role of nursing leadership is the creation of strategies that promote healthy and nurturing environments for the NLRN that are conducive to a successful transition to practice. Consideration of the implications of an unhealthy work environment and the outcomes on NLRNs is an important role of nursing leaders. If a negative, or unhealthy work environment exists, a culture of bullying can be cultivated and perpetuated.

Without an understanding and constant cultivation of effective preceptors and healthy work environments, nursing leadership must be prepared to endure the results of turnover and orientation costs. The negative effects on the NLRN may also expand to the remaining nursing staff. Providing a healthy work environment for the NLRN should be a major concern for experienced nurses and nursing leadership.

Education. Just as important as nursing practice implications, educational implications for successful NLRN transition and retention must be considered. The research findings in this study illustrate the importance of effective preceptor education and preparation. There are several factors that create an effective preceptor, one of the most important is adequate preceptor preparation and teaching. There are several important components to address in a preceptor education program. For example, the American Association of Critical-Care Nurses (AACN) (2014) has created a Preceptor Challenge initiative that discusses the essential needs in a preceptor education program. The components of the course include: learning style education, information on preceptor balancing of staff nurse and preceptor pressures, as well as creating a preceptee learning program.

Another factor to consider is the perception of preceptor readiness. Chang, Lin, Chen, 
Kang, and Chang (2014) found three themes in preceptor feedback from training courses. The themes included: inadequate training was received before nurses were appointed as nurse preceptors, the courses were more theoretical rather than practical, and the preceptors experienced stress from multiple environmental and staff sources on the floor. Nursing leadership should continue to strive in creating the most effective and equipped nurse preceptors, making selecting the most appropriate preceptor training courses a top priority.

Another educational implication of this research study is creating successful residency programs. An effective residency allows for low-pressure NLRN education with the ability for the NLRN to network with others on patient and work-life experiences. A primary benefit of a residency program is to equip healthcare systems with improved nurse retention rates. An example of a residency program is the United Healthcare Consortium (UHC)/AACN nurse residency initiative (AACN, 2001). The initiative was created as an effort to standardize the residency process, and resulted in a 94.3\% retention rate among NLRNs? Standardized evidencebased curriculum is offered to the NLRN to reduce the emotional shock of transition during the first year of practice (AACN, 2001). Residency programs have been demonstrated to be effective in areas of NLRN intent to stay and job satisfaction (Laschinger, 2012).

The third educational implication is for the need of effective mentorship programs. According to Benner's From Novice to Expert: Excellence and Power in Nursing Clinical Practice (2011), it takes two years for a novice, or NLRN, to reach a level of competence. Formal residency programs only occur during the NLRNs' first year of practice, leaving another year for the NLRN to transition to the level of a competent practicing nurse. Failing to provide NLRNs with support would be a disservice as they complete the transition from novice to competent nurse. A focus of nursing leadership is to account for the group cohesion of the NLRN 
and anticipate NLRN support needs. A formal mentorship program may aid in easing the transition to practice for the NLRN while providing a formal support structure that does not have daily impact on practice. Benefits of formal mentorship programs have been reported to include increased job satisfaction and group cohesion among NLRNs (Mills \& Mullins, 2008).

Future research. This study uncovers the potential for further research surrounding the transition of the NLRN. A longitudinal study following NLRNs through the first year of transition may aid in uncovering areas of weaknesses and strengths during this phase of orientation. A study of this magnitude may aid in pinpointing challenges during the transition, characteristics of successful transitions, and development of best practices to better adapt residency and orientation processes.

Another implication for future research is examining unit and group dynamics. This type of study may identify successful group cohesion traits as well as understanding NLRN needs for successful transition. A third implication is in analyzing the differences between formal and informal mentorship programs. The implications of a mentorship program could have reaches beyond the life of the NLRN, and could aid in further understanding factors to improve work environment. The most effective mentorship program will match the mentor and mentee based on similar areas of work and shift type.

The last research implication is in defining successful preceptorship characteristics. While many factors exist in creating a successful and effective preceptorship, specific characteristics, such as personality traits and leadership styles can be better defined. Defining key effective preceptorship characteristics can be vital in grooming NLRNs towards a successful transition to professional practice as well as creating criteria for experienced RNs in order to become preceptors. Effective and positive preceptorship experiences aid in the NLRN perception of 
practice ability.

\section{Conclusion}

The goal of this research study was to examine the NLRNs' perceived levels and relationships between preceptor role effectiveness, group cohesion, job satisfaction and intent to stay. The study indicated that NLRNs perceived high levels of preceptor role effectiveness, group cohesion, and job satisfaction, but only moderate levels of intent to stay. Effective preceptors and positive group cohesion are factors that are important to NLRNs' job satisfaction and intent to stay. An important role for nursing leaders is to identify successful strategies to ease the transition to practice for NLRNs. With proper implementation, nursing leaders can expect some insulation from the global nursing shortage, improved patient outcomes, and increased cost savings from proper NLRN training and retention strategies. 


\section{REFERENCES}

American Association of Colleges of Nursing. (2001) AACN/ UHC: Executive summary of the post-baccalaureate residency program. $A A C N$. Retrieved from:

http://www.aacn.nche.edu/leading-initiatives/educationresources/NurseResidencyProgramExecSumm.pdf.

American Association of Critical-Care Nurses (2014). The preceptor challenge. AACN. Retrieved from: http://www.aacn.org/WD/ELearning/content/preceptor/preceptor.pcms?menu=Elearning.

Beecroft, P., Dorey, F., \& Wenten, M. (2008). Turnover intention in new graduate nurses: A multivariate analysis. Journal of Advanced Nursing, 62(1), 41-52. doi:10.1111/j.13652648.2007.04570.

Benner, P.E. (2001). From novice to expert: Excellence and power in clinical nursing practice. Upper Saddle River, N.J.: Prentice Hall, 2001.

Bogaert, P., Kowalski, C., Weeks, S., Heusden, D., \& Clarke, S. P. (2013). The relationship between nurse practice environment, nurse work characteristics, burnout and job outcome and quality of nursing care: A cross-sectional survey. International Journal of Nursing Studies, 50(12), 1667-1677. doi:10.1016/j.ijnurstu.2013.05.010.

Boyle D.K., Bott M.J., Hansen H.E., Woods C.Q. \& Taunton R.L. (1999) Managers' leadership and critical care nurses' intent to stay. American Journal of Critical Care 8(6), 361-371.

Brewer, C. S., Kovner, C. T., Greene, W., Tukov-Shuser, M., \& Djukic, M. (2012). Predictors of actual turnover in a national sample of newly licensed registered nurses employed in hospitals. Journal of Advanced Nursing, 68(3), 521-538. doi:10.1111/j.13652648.2011.05753. 
Burket, T., Felmlee, M., Greider, P., Hippensteel, D., Rohrer, E., \& Shay, M. (2010). Clinical ladder program evolution: Journey from novice to expert to enhancing outcomes. Journal of Continuing Education in Nursing, 41(8), 369-374. doi:10.3928/00220124-2010050307.

Byrne, D. (1961). Interpersonal attraction and attitude similarity. Journal of Abnormal and Social Psychology, 62,713-715.

Chang, C., Lin, L., Chen, I., Kang, C., \& Chang, W. (2014). Perceptions and experiences of nurse preceptors regarding their training courses: A mixed method study. Nurse Education Today, doi:10.1016/j.nedt.2014.08.002.

Colazzi, P. (1978). Psychological research as the phenomenologist view it. Existentialphenomenological alternatives for psychology. Oxford University Press: New York, pp. $48-71$.

Cowden, T. L., \& Cummings, G. G. (2012). Nursing theory and concept development: A theoretical model of clinical nurses' intentions to stay in their current positions. Journal of Advanced Nursing, 68(7), 1646-1657. doi:10.1111/j.1365-2648.2011.05927.

Faul, F., Erdfelder, E., Buchner, A., \& Lang, A. G. (2009). Statistical power analyses using G*Power 3.1: Tests for correlation and regression analyses. Behavior Research Methods, 41, 1149-1160.

Feng, R. \& Tsai, Y. (2012). Socialization of the new graduate nurse to practicing nurses. Journal of Clinical Nursing 21, 2064-2071.

Forneris, S. \& Peden-McAlpine, C. (2009). Creating context for critical thinking in practice: The role of the preceptor. Journal of Advanced Nursing, 65(8), 1715-1724. 
Fox, R., Henderson, A., \& Malko-Nyhan, K. (2006). A comparison of preceptor and preceptee's perceptions of how the preceptor's role is operationalized. Journal of Clinical Nursing, 15(3), 361-364.

Giallonardo, L., Wong, C., \& Iwasiw, C. (2010). Authentic leadership of preceptors: Predictors of new graduate nurses' work engagement and job satisfaction. Journal of Nursing Management, 18, 993-1003.

Glynn, P, \& Silva, S. (2013). Meeting the needs of new graduates in the emergency department: A qualitative study evaluating a new graduate internship program. Journal of Emergency Nursing, 39(2), 173-178.

Haggerty, C., Holloway, K., \& Wilson, D. (2013). How to grow our own: An evaluation of preceptorship in New Zealand graduate nurse programmes. Contemporary Nurse, 43(2), $162-171$.

Halfer, D., Graf, E., \& Sullivan, C. (2008). The organizational impact of a new graduate pediatric nurse mentoring program. Nursing Economic\$, 26(4), 243-249.

Hillman, L., \& Foster, R. (2011). The impact of a nursing transitions programme on retention and cost savings. Journal of Nursing Management, 19(1), 50-56. doi:10.1111/j.13652834.2010.01187.

Hinshaw, A. S. \& Atwood J. R. (1983). Nursing staff turnover, stress, and satisfaction: Models, measures, and management. Annual Review of Nursing Research, 1, 1133-1153.

Jones, C., \& Gates, M., (2007). The costs and benefits of nurse turnover: A business case for nurse retention. OJIN: The Online Journal of Issues in Nursing. 12(3), Manuscript 4. Retrieved from http://nursingworld.org/MainMenuCategories/ANAMarketplace /ANAPeriodicals/OJIN/TableofContents/Volume122007/No3Sept07/NurseRetention.asp $\mathrm{x}$. 
Kim, S., Price, J. L., Mueller, C. W., \& Watson, T. W. (1996). The determinants of career intent among physicians at a U.S. Air Force Hospital. Human Relations, 49, 947976.

Kovner, C., Brewer, C., Fairchild, S., et al. (2009). Newly licensed RNs' characteristics, work attitudes, and intentions to work. American Journal of Nursing, 107 (9), 58-70.

Kovner, C., Brewer, C., Greene, W., \& Fairchild, S. (2009). Understanding new registered nurses' intent to stay at their jobs. Nursing Economic\$, 27(2), 81-98.

Kowitlawakul, Y. (2013). From novice to expert: Sharing professional development experience in different practice settings. Singapore Nursing Journal, 40(3), 43-46.

Laschinger, H. (2012). Job and career satisfaction and turnover intentions of newly graduated nurses. Journal of Nursing Management, 20(4), 472-484. doi:10.1111/j.13652834.2011.01293.

Lavoie-Tremblay, M., O'Brien-Pallas, L., Gelinas, C., Desforges, N., \& Marchionni, C. (2008). Addressing the turnover issue among new nurses from a generational viewpoint. Journal of Nursing Management, 16(6), 724-733. doi:10.1111/j.1365-2934.2007.00828.

Li, A., Early, F., Mahrer, N., Klaristenfeld, J., \& Gold, J. (2014). Group cohesion and organizational commitment: Protective factors for nurse residents' job satisfaction, compassion fatigue, and burnout. Journal of Professional Nursing, 30(1), 89-99.

Lee, T., Tzeng, W., Lin, C., \& Yeh, M. (2009). Effects of a preceptorship programme on turnover rate, cost, quality and professional development. Journal of Clinical Nursing, 18(8), 1217-1225. doi:10.1111/j.1365-2702.2008.02662.

Luhanga, F., Dickleson, P., \& Mossey, S. (2010). Preceptor preparation: An investment in the future generation of nurses. International Journal of Nursing Education Scholarship, 
7(1): 1P, 1-18.

Malouf, N. \& West, S. (2010). Fitting in: A pervasive new graduate nurse need. Nurse Education Today, 31, 488-493.

Martin, K. \& Wilson, C. (2011). Newly licensed registered nurses' experience in the first year of practice: A phenomenological study. International Journal for Human Caring, 15(2), 21 27.

McKenna, L. \& Newton, J. (2008). After the graduate year: A phenomenological exploration of how new nurses develop their knowledge and skill over the first 18 month following graduation. Australian Journal of Advanced Nursing, 25(4), 9-15.

Mills, J. F., \& Mullins, A. C. (2008). The California Nurse Mentor Project: Every nurse deserves a mentor. Nursing Economic\$, 26(5), 310-315.

Mihyun, P., Ji Yun, L., \& Sung-Hyun, C. (2012). Newly graduated nurses' job satisfaction: Comparison with allied hospital professionals, social workers, and elementary school teachers. Asian Nursing Research, 6(3), 85-90.

Phillips, C., Kenny, A., Esterman, A., \& Smith, C. (2013). A secondary data analysis examining the needs of graduate nurses in their transitions to a new role. Nurse Education in Practice, 14, 106-111.

Price, J. L. (2000). Reflection on the determinants of voluntary turnover. International Journal of Manpower, 22(6), 600-624.

Raines, D. \& Lynn, C (2009). Do nurse preceptors care? International Journal for Human Caring, 33(4), 33-7.

Rauen, K. (1974). The clinical instructor as a role model. Journal of Nursing Education, 3(1974), 33-40. 
Rosseter, R. (2014). American association of colleges of nursing: Nursing shortage fact sheet. Retrieved from http://www.aacn.nche.edu/media-relations/fact-sheets/nursing-shortage. Spiva, L., Hart, P., Pruner, L., Johnson, D., Martin, K., Brakovich, B., McVay, F., \& Mendoza, S. (2013). Hearing the voices of newly licensed RNs: The transition to practice. The American Journal of Nursing, 113(11), 24-32.

Singer, C. (2006). A preceptor training program model for the hemodialysis setting. Nephrology Nursing Journal, 33(6), 623-630.

Stake, R.E. (1995). The art of case study research. Thousand Oaks, CA: Sage Publications.

Tourangeau A. E. \& Cranley L. A. (2006) Nurse intention to remain employed: Understanding and strengthening determinants. Journal of Advanced Nursing 55(4), 497-509.

Tourangeau, A., Cranley, L., Spence Laschinger, H. K., \& Pachis, J. (2010). Relationships among leadership practices, work environments, staff communication and outcomes in long-term care. Journal of Nursing Management, 18(8), 1060-1072. doi:10.1111/j.13652834.2010.01125.

Trepanier, S., Early, S., Ulrich, B., \& Cherry, B. (2012). New graduate nurse residency program: A cost-benefit analysis based on turnover and contract labor usage. Nursing Economic\$, 30(4), 207.

Wang, L., Tao, H., Ellenbecker, C., \& Liu, X. (2012). Job satisfaction, occupational commitment and intent to stay among Chinese nurses: a cross-sectional questionnaire survey. Journal of Advanced Nursing, 68(3), 539-549. doi:10.1111/j.1365-2648.2011.05755.

Zinn, J., Gugliemi, C., Davis, P., \& Moses, C. (2012). Addressing the nursing shortage: The need for the nurse residency programs. AORN Journal, 96(6), 652-657. doi:10.1016/j.aorn.2012.09.011. 
Appendix A

Permission to Survey NLRNs 
From: Wingel, Ruth <Ruth.Wingel@wellstar.org>

Date: Fri, Jul 25, 2014 at 6:48 AM

Subject: RE: Grad school research

To: Sarah Bontrager <schapm28@ gmail.com>

Sarah,

I am excited about your project. I welcome you coming to the residency and surveying the new graduates. I look forward to learning the results as this is very good

information. Please set up a time for us to meet to discuss the particulars.

Ruth Wingel, MSN, RN

From: Sarah Bontrager [schapm28@gmail.com]

Sent: Wednesday, July 23, 2014 10:57 PM

To: Wingel, Ruth

Subject: Grad school research

Ruth,

I have briefly spoken to you in regards to my thesis. I plan on surveying the NLRNs in regards to their level of job satisfaction, intent to stay, preceptor role effectiveness, and group cohesion. I was planning on setting up the computer lab for several cohorts of NLRNs (need 84 participants) and having them complete a survey monkey, if that is still ok with you. This will only take about 15 minutes, if you do not mind me hijacking the NLRNs for that period of time.

After speaking with my thesis advisor I was wondering if you could send me some kind of acknowledgement that we have talked. If you are willing to let me survey the new graduates please include that as well. I will still be going in front of KSU's IRB as well as WellStar's research committee, but we feel that a statement/ acknowledgement of consent(email or letter) from you will help ensure the process will go smoother.

If there is a problem or if you have questions please let me know! I am hoping to start surveying in thebegiining to middle of September. 404-368-5419. Thanks again!

Sarah Bontrager RN, BSN 
Appendix B

Emailed Survey Notification 


\section{Initial Survey Solicitation}

“Dear Newly Licensed Registered Nurse:

My name is Sarah Bontrager and I am a nurse at WellStar that is also seeking an MSN: Nursing Administration and Health Policy degree at Kennesaw State University. One of the requirements for my track is to conduct research in a nursing area. I have chosen to conduct research on the new nurse experience. I am seeking 84 newly licensed registered nurses to participate in my research study. The survey is completed through a Survey Monkey questionnaire and will only take 15 minutes to complete. The survey is completely anonymous. The survey link is:

Detailed information is provided about the study once you click on the link. I thank you for your participation. If there are any question about this research please feel free to contact me as listed in the Survey monkey link.

\section{Follow-Up Survey Solicitation}

"Newly Licensed Registered Nurse:

My name is Sarah Bontrager and I am a WellStar nurse as well as a graduate student seeking my MSN in Nursing Administration and Health Policy. I contacted you two weeks ago to inform you about a research study I am conducting. If you have already completed the survey, I thank you for your participation. Part of my education involves completing research on a nursing area of my choosing. I have decided to study the new nurse experience. Please let me know, by completing this survey, what your experience is as a newly practicing nurse. The survey is completed through a Survey Monkey questionnaire and will only take 15 minutes to complete. The survey is completely anonymous. If you have any questions or concerns please contact me through the information provided in after clicking on the survey link. The link is: 
Appendix C

Demographic Questionnaire 


\section{Demographic Questionnaire}

1. What is your gender? $\square$ Male $\square$ Female

2. What is your age, in years?

3. What race/ethnicity group do you most identify with?

$\square$ White/Caucasian $\quad \square$ Black/African-American

$\square$ Hispanic/Latino $\square$ Asian or Pacific Islander

$\square$ Native American $\quad \square$ Arabic

$\square$ Other

4. How many months have you been licensed as a Registered Nurse (RN)?

5. In what area do you practice?

$\square$ Acute Care $\square$ Critical Care

$\square$ Womens Services $\square$ Emergency Department

$\square$ Other

6. What shift will you work or do you work after your orientation?

$\begin{array}{ll}\square 7 \mathrm{a}-7 \mathrm{p} & \square 7 \mathrm{p}-7 \mathrm{a} \\ \square 7 \mathrm{a}-3 \mathrm{p} & \square 3 \mathrm{p}-11 \mathrm{p} \\ \square 11 \mathrm{p}-7 \mathrm{a} & \square \text { Other }\end{array}$

7. Did the first employer whom hired you after you were licensed offer you a one-on-one preceptorship with an experienced nurse (preceptor)?

$\square$ Yes $\quad \square$ No

8. Did you work in a healthcare setting prior to your first nursing position?

$\square$ Yes $\quad \square$ No 
Appendix D

Preceptor Effectiveness Scale 


\section{Preceptor Role Effectiveness Scale}

The following items describe preceptor role characteristics. The items are designed to determine the effectiveness of your preceptor. The statements are to be applied to the first preceptor you were assigned during this preceptorship period only. You are asked to respond to each item according to how you would rank the presence of each characteristic in your first preceptor during your preceptorship only.

Please select the number that represents the degree to which you agree or disagree with each statement.

\begin{tabular}{|c|c|c|c|c|}
\hline & $\begin{array}{l}\text { Strongly } \\
\text { Disagree }\end{array}$ & Disagree & Agree & $\begin{array}{l}\text { Strongly } \\
\text { Agree }\end{array}$ \\
\hline $\begin{array}{l}\text { 1. Was available for help when I needed } \\
\text { guidance }\end{array}$ & 1 & 2 & 3 & 4 \\
\hline $\begin{array}{l}\text { 2. Demonstrated knowledge of scientific } \\
\text { principles relative to patient care }\end{array}$ & 1 & 2 & 3 & 4 \\
\hline $\begin{array}{l}\text { 3. Showed genuine interest in me as an } \\
\text { individual }\end{array}$ & 1 & 2 & 3 & 4 \\
\hline $\begin{array}{l}\text { 4. Gave assignments that helped me transfer } \\
\text { theoretical concepts to actual patient care }\end{array}$ & 1 & 2 & 3 & 4 \\
\hline $\begin{array}{l}\text { 5. Demonstrated ability to do nursing skills (such } \\
\text { as nursing procedures) }\end{array}$ & 1 & 2 & 3 & 4 \\
\hline $\begin{array}{l}\text { 6. Encouraged me to be "open" thereby } \\
\text { respecting my opinions and feelings. }\end{array}$ & 1 & 2 & 3 & 4 \\
\hline 7. Demonstrated honesty to me and others & 1 & 2 & 3 & 4 \\
\hline $\begin{array}{l}\text { 8. Demonstrated ability to use scientific } \\
\text { principles relative to patient care. }\end{array}$ & 1 & 2 & 3 & 4 \\
\hline $\begin{array}{l}\text { 9. Suggested helpful resources when I have } \\
\text { questions. }\end{array}$ & 1 & 2 & 3 & 4 \\
\hline $\begin{array}{l}\text { 10. Demonstrated how to function in a real } \\
\text { nursing situation. }\end{array}$ & 1 & 2 & 3 & 4 \\
\hline 11. Avoided embarrassing me. & 1 & 2 & 3 & 4 \\
\hline 12. Encouraged me to think for myself. & 1 & 2 & 3 & 4 \\
\hline $\begin{array}{l}\text { 13. Showed a contagious enthusiasm for giving } \\
\text { quality patient care }\end{array}$ & 1 & 2 & 3 & 4 \\
\hline $\begin{array}{l}\text { 14. Evaluated my progress in nursing in a fair } \\
\text { manner. }\end{array}$ & 1 & 2 & 3 & 4 \\
\hline $\begin{array}{l}\text { 15. Rewarded my efforts to give quality nursing } \\
\text { care. }\end{array}$ & 1 & 2 & 3 & 4 \\
\hline 16. Showed empathy to others and me. & 1 & 2 & 3 & 4 \\
\hline $\begin{array}{l}\text { 17. Demonstrated kindness during daily } \\
\text { interactions with people. }\end{array}$ & 1 & 2 & 3 & 4 \\
\hline $\begin{array}{l}\text { 18. Showed a continued interest in applying } \\
\text { improved methods of giving nursing care. }\end{array}$ & 1 & 2 & 3 & 4 \\
\hline
\end{tabular}


Appendix E

Group Cohesion Scale 


\section{Group Cohesion Scale}

The following six items ask for your opinion about the colleague group (nursing staff) with whom you work on your nursing unit. For each item below, select the appropriate response.

\begin{tabular}{|c|c|c|c|c|c|c|c|}
\hline & $\begin{array}{c}\text { Very } \\
\text { much } \\
\text { below } \\
\text { average }\end{array}$ & $\begin{array}{c}\text { Below } \\
\text { average }\end{array}$ & $\begin{array}{c}\text { Slightly } \\
\text { below } \\
\text { average }\end{array}$ & Average & $\begin{array}{l}\text { Slightly } \\
\text { above } \\
\text { average }\end{array}$ & $\begin{array}{c}\text { Above } \\
\text { average }\end{array}$ & $\begin{array}{c}\text { Very } \\
\text { much } \\
\text { above } \\
\text { average }\end{array}$ \\
\hline $\begin{array}{l}\text { 1. I believe the } \\
\text { productivity of this } \\
\text { group is: }\end{array}$ & 1 & 2 & 3 & 4 & 5 & 6 & 7 \\
\hline $\begin{array}{l}\text { 2. I believe the } \\
\text { efficiency of this } \\
\text { group is: }\end{array}$ & 1 & 2 & 3 & 4 & 5 & 6 & 7 \\
\hline $\begin{array}{l}3 . \text { I believe the } \\
\text { morale of this } \\
\text { group is: }\end{array}$ & 1 & 2 & 3 & 4 & 5 & 6 & 7 \\
\hline \multirow{2}{*}{$\begin{array}{l}\text { 4. I believe the } \\
\text { feelings of } \\
\text { belongingness in } \\
\text { this group is: }\end{array}$} & 1 & 2 & 3 & 4 & 5 & 6 & 7 \\
\hline & $\begin{array}{l}\text { Dislike } \\
\text { it very } \\
\text { much }\end{array}$ & $\begin{array}{c}\text { Dislike } \\
\text { it }\end{array}$ & $\begin{array}{l}\text { Dislike } \\
\text { it } \\
\text { slightly }\end{array}$ & $\begin{array}{l}\text { Neither } \\
\text { particul } \\
\text { arly like } \\
\text { it or } \\
\text { dislike it }\end{array}$ & $\begin{array}{c}\text { Like it } \\
\text { slightly }\end{array}$ & Like it & $\begin{array}{c}\text { Like it } \\
\text { very } \\
\text { much }\end{array}$ \\
\hline $\begin{array}{l}\text { 5. In terms of } \\
\text { personal feelings } \\
\text { about this group, I } \\
\text { feel I: }\end{array}$ & 1 & 2 & 3 & 4 & 5 & 6 & 7 \\
\hline $\begin{array}{l}\text { 6. In terms of } \\
\text { working together } \\
\text { on this unit with } \\
\text { this group, I } \\
\text { believe I: }\end{array}$ & 1 & 2 & 3 & 4 & 5 & 6 & 7 \\
\hline
\end{tabular}


Appendix F

Nurse Job Satisfaction Scale 


\section{Nurse Job Satisfaction Scale}

For each item below, please circle the appropriate response.

\begin{tabular}{|c|c|c|c|c|c|}
\hline & $\begin{array}{l}\text { Strongly } \\
\text { Disagree }\end{array}$ & Disagree & Undecided & Agree & $\begin{array}{c}\text { Strongly } \\
\text { Agree }\end{array}$ \\
\hline $\begin{array}{l}\text { 1. Most days I have time to provide } \\
\text { hygiene measures for my patients. }\end{array}$ & 1 & 2 & 3 & 4 & 5 \\
\hline 2. I consider my job rather unpleasant. & 1 & 2 & 3 & 4 & 5 \\
\hline $\begin{array}{l}\text { 3. Usually I have enough time to do a } \\
\text { good job of patient care. }\end{array}$ & 1 & 2 & 3 & 4 & 5 \\
\hline $\begin{array}{l}\text { 4. I enjoy my work more than my } \\
\text { leisure time. }\end{array}$ & 1 & 2 & 3 & 4 & 5 \\
\hline $\begin{array}{l}\text { 5. Many days I would have to stay } \\
\text { overtime to get all my paper/computer } \\
\text { work done. }\end{array}$ & 1 & 2 & 3 & 4 & 5 \\
\hline $\begin{array}{l}\text { 6. Many days I feel harassed because } \\
\text { I don't have time to do all I want to } \\
\text { do. }\end{array}$ & 1 & 2 & 3 & 4 & 5 \\
\hline $\begin{array}{l}\text { 7. I feel fairly well satisfied with my } \\
\text { present job. }\end{array}$ & 1 & 2 & 3 & 4 & 5 \\
\hline $\begin{array}{l}\text { 8. I am not satisfied with the level of } \\
\text { individualized care I am now giving. }\end{array}$ & 1 & 2 & 3 & 4 & 5 \\
\hline $\begin{array}{l}\text { 9. Most of the time I have to force } \\
\text { myself to go to work. }\end{array}$ & 1 & 2 & 3 & 4 & 5 \\
\hline $\begin{array}{l}\text { 10. Under the circumstances it is } \\
\text { difficult to provide high quality of } \\
\text { care. }\end{array}$ & 1 & 2 & 3 & 4 & 5 \\
\hline $\begin{array}{l}\text { 11. I am satisfied with my job for the } \\
\text { time being. }\end{array}$ & 1 & 2 & 3 & 4 & 5 \\
\hline 12. I definitely dislike my work. & 1 & 2 & 3 & 4 & 5 \\
\hline $\begin{array}{l}\text { 13. I feel that I am happier than most } \\
\text { other people. }\end{array}$ & 1 & 2 & 3 & 4 & 5 \\
\hline $\begin{array}{l}\text { 14. Most of the time I am satisfied } \\
\text { with patient care that I give. }\end{array}$ & 1 & 2 & 3 & 4 & 5 \\
\hline $\begin{array}{l}\text { 15. Most days I am enthusiastic about } \\
\text { my work. }\end{array}$ & 1 & 2 & 3 & 4 & 5 \\
\hline
\end{tabular}




\begin{tabular}{|c|c|c|c|c|c|}
\hline & $\begin{array}{l}\text { Strongly } \\
\text { Disagree }\end{array}$ & Disagree & Undecided & Agree & $\begin{array}{c}\text { Strongly } \\
\text { Agree }\end{array}$ \\
\hline $\begin{array}{l}\text { 16. It is hard for me to give patient } \\
\text { care which meets my standards. }\end{array}$ & 1 & 2 & 3 & 4 & 5 \\
\hline $\begin{array}{l}\text { 17. I like my job better than the } \\
\text { average worker does. }\end{array}$ & 1 & 2 & 3 & 4 & 5 \\
\hline 18. I find real enjoyment in my work. & 1 & 2 & 3 & 4 & 5 \\
\hline $\begin{array}{l}\text { 19. I am disappointed that I ever took } \\
\text { this job. }\end{array}$ & 1 & 2 & 3 & 4 & 5 \\
\hline $\begin{array}{l}\text { 20. There are some conditions } \\
\text { concerning my job that could be } \\
\text { improved. }\end{array}$ & 1 & 2 & 3 & 4 & 5 \\
\hline $\begin{array}{l}21 . \text { I feel I have time to do both the } \\
\text { paper/computer work and my patient } \\
\text { care. }\end{array}$ & 1 & 2 & 3 & 4 & 5 \\
\hline $\begin{array}{l}\text { 22. I feel satisfied with the technical } \\
\text { care I give. }\end{array}$ & 1 & 2 & 3 & 4 & 5 \\
\hline $\begin{array}{l}\text { 23. I am able to keep my patients } \\
\text { comfortable. }\end{array}$ & 1 & 2 & 3 & 4 & 5 \\
\hline
\end{tabular}


Appendix G

Intent to Stay Scale 


\section{Intent to Stay Scale}

Please circle the number that best reflects your opinion.

\begin{tabular}{|l|c|c|c|c|c|}
\hline & $\begin{array}{l}\text { Strongly } \\
\text { Disagree }\end{array}$ & Disagree & Undecided & Agree & $\begin{array}{c}\text { Strongly } \\
\text { Agree }\end{array}$ \\
\hline $\begin{array}{l}\text { 1. I would like to leave my } \\
\text { present employer. }\end{array}$ & 1 & 2 & 3 & 4 & 5 \\
\hline $\begin{array}{l}\text { 2. I plan to leave my present } \\
\text { employer as soon as possible. }\end{array}$ & 1 & 2 & 3 & 4 & 5 \\
\hline $\begin{array}{l}\text { 3. I plan to stay with my } \\
\text { present employer as long as } \\
\text { possible. }\end{array}$ & 1 & 2 & 3 & 4 & 5 \\
\hline $\begin{array}{l}\text { 4. Under no circumstances will } \\
\text { I voluntarily leave my present } \\
\text { employer. }\end{array}$ & 1 & 2 & 3 & 4 & 5 \\
\hline
\end{tabular}


Appendix $\mathbf{H}$

Permission to Use CICRS 
From: Rauen, Karen <KRauen@chw.org>

Date: Tue, Dec 10, 2013 at 3:21 PM

Subject: RE: Clinical Instructor Characteristics Ranking Scale

To: Sarah Bontrager <schapm28@gmail.com>

Dear Ms. Bontrager,

You have my permission to use the CICRS for you study, and adapt it in any way you wish, as long a I am credited with the original Clinical Instructor Characteristics Ranking Scale.

Best Wishes, Karen Rauen, MSN, RN

From: Sarah Bontrager [schapm28@gmail.com]

Sent: Monday, December 09, 2013 4:36 PM

To: Rauen, Karen

Subject: Clinical Instructor Characteristics Ranking Scale

Ms Rauen

I am conducting a research study for my thesis requirements, and I am seeking permission to use the Clinical Instructor Characteristics Ranking Scale in my research study. I would also like to have permission to adapt the instrument for use in my study. I will be sure and credit you as the instrument's author in my study. Please let me know if I have your permission to use the scale in my study. Thank you for your time and consideration with this request. 
Appendix I

Permission to Use Group Cohesion Scale 
From: Patricia Handel <patricia.handel@usuhs.edu>

Date: Thu, Jan 30, 2014 at 7:26 AM

Subject: FW: Group Cohesion Scale

To: schapm28@gmail.com

Ms. Bontrager,

I'm sending this a second time; the first one came back to me as "address not available". Even though it might have passed our various fire walls, it might have gotten hung up somewhere along the line. Attached is a copy of the Group Cohesion Scale request by you and approval from Dr. Hinshaw and Dr. Atwood. Good luck with your research!

Mrs. Ticia Handel

Executive Secretary to the Dean

Daniel K. Inouye Graduate School of Nursing 
Appendix J

Permission to Use Nurse Job Satisfaction 
From: Patricia Handel <patricia.handel@usuhs.edu>

Date: Fri, Jan 24, 2014 at 3:04 PM

Subject: FW: Nurse Job Satisfaction Scale

To: schapm28@gmail.com

Ms. Bontrager,

Attached is a copy of the Nurse Job Satisfaction Scale referred to in your message, as well as Dr. HInshaw's message.

Good Luck with your research!

Mrs. Ticia Handel

From: Ada Hinshaw [mailto:ada.hinshaw@usuhs.edu]

Sent: Friday, January 24, 2014 1:35 PM

To: Sarah Bontrager

Cc: atwoodj@comcast.net; A.Hinshaw, USU, GSN

Subject: RE: Nurse Job Satisfaction Scale

Dr. Atwood and I would be pleased for you to use the Nurse Job Satisfaction Scale. Ms. Handel will send you the packet with the instrument and the early psychometric testing results. Best of success with your research! 
Appendix K

WellStar NRC Approval Letter 


\section{WELLSTAR。}

From: Jayne Petefish, RN, MS, $\Lambda$ CNS-BC

To: Sarah Bontrager

Date: 8-27-14

Subject: NRC Approval for Study 14-11

Dear Ms. Bontrager:

Study Number: 14-11

Study Title: The Role of Preceptorship and Group Cohesion in Newly Licensed Registered Nurses' Satisfaction and Intent to Stay

Your research proposal was approved by the WellStar Nursing Rescarch Committec on August 25,2014 . You may begin your study as described effective immediately. We need you to lax a copy of your IRB approval once it has been received and any changes to the study must be reported promptly to the Nursing Rescarch Committee for approval.

A Progress Report (download from the Center for Nursing Excellence website) is due in August, 2015 unless the study is closed belore that date. At the completion of the study, please contact me to schedule a date to report the results of your study to the Nursing Research Committee.

Plcase contact me if you have any questions or need additional information.

Best wishes for your rescarch,

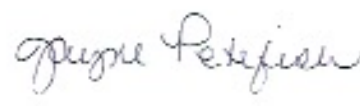

Jayne Petefish MS, ACNS-BC

Wellstar Kennestone Medical Center

Clinical Nurse Specialist

Surgical/Irauma

Chair WellStar Research Committec

677 Church St.

Marietta, G^ 30060

Oflice 770793-9902 
Appendix L

Kennesaw State IRB Approval Letter 
From: <zieglerirb@kennesáw.edu>

Date: Fri, Sep 5, 2014 at 3:51 PM

Subject: Study 15-077: The Role of Preceptorship and Group Cohesion on Newly Licensed Registered Nurses' Satisfaction and Intent to Stay

To: schapm28@gmail.com

cc: zieglerirb@kennesaw.edu

$9 / 5 / 2014$

Sarah Bontrager

RE: Your application dated 8/28/2014, Study \#15-077: The Role of Preceptorship and Group Cohesion on Newly Licensed Registered Nurses' Satisfaction and Intent to Stay

Dear Ms. Bontrager:

Your application for the new study listed above has been administratively reviewed. This study qualifies as exempt from continuing review under DHHS (OHRP) Title 45 CFR Part 46.101(b)(2) - educational tests, surveys, interviews, public observations. The consent procedures described in your application are in effect. You are free to conduct your study.

Please note that all proposed revisions to an exempt study require IRB review prior to implementation to ensure that the study continues to fall within an exempted category of research. A copy of revised documents with a description of planned changes should be submitted to irb@kennesaw.edu for review and approval by the IRB.

Thank you for keeping the board informed of your activities. Contact the IRB at irb_@ennesaw.edu or at (678) $797-2268$ if you have any questions or require further information.

Sincerely,

Christine Ziegler, Ph.D.

KSU Institutional Review Board Chair

cc: phart(okennesaw.edu 
Appendix M

Consent Form 


\section{The Effects of NLRN Perceptions of Group Cohesion and Preceptor Effectiveness on Intent to Stay and Nursing Satisfaction.}

Investigator Contact Information: Sarah Bontrager, (404)368-5419, schapm28@gmail.com

You are being invited to take part in a research study conducted by Sarah Bontrager of Kennesaw State University. Before you decide to participate in this study you should read this form and ask questions about anything you do not understand.

The purpose of this study is to explore the relationships between newly licensed registered nurses' perceptions of preceptor role effectiveness and perceived levels of group cohesion, job satisfaction, and intent to stay. With these variables more closely evaluated, possible strategies and changes can be addressed to further aid newly licensed registered nurses during this challenging transition period.

You will be asked to participate in an online survey. You will complete a short demographic form and four other surveys. Once you have read the instructions and if you consent to participate, please do so by clicking the appropriate selection below and then clicking the most appropriate boxes that follow. It will take about 15 to 20 minutes to complete.

There is no known risks or anticipated discomforts by participating in this study. Although there may not be any direct benefit to you for taking part in this study, the researcher may learn more about the transition period for newly licensed registered nurses and develop strategies to ensure a successful transition to clinical nursing practice.

This survey is anonymous. If you choose to participate, no identifying information or IP addresses will be collected. No one will be able to identify you, nor will anyone be able to determine which WellStar campus you work for. No one will know whether you participated in this study. Your participation or lack of participation will not affect your residency program or orientation experience. Nothing you say on the questionnaire will in any way influence your present or future employment with your company.

To participate you must be 18 years of age or older. You must also be participating in your first year of nursing and enrolled in WellStar Health System's residency courses. You must be practicing at one of WellStar's hospitals and are able to read English at an $8^{\text {th }}$ grade level or higher.

Research at Kennesaw State University that involves human participants is carried out under the oversight of and Institutional Review Board. Questions or problems regarding these activities should be addressed to the Institutional Review Board, Kennesaw State University, 1000 Chastain Road, Kennesaw, GA, 30144-5591, (678) 797-2298.

PLEASE PRINT A COPY OF THIS CONSENT DOCUMENT FOR YOUR RECORDS, OR IF YOU DO NOT HAVE PRINT CAPABILITIES, YOU MAY CONTACT THE RESEARCHER TO OBTAIN A COPY 
$\square$ I agree and give my consent to participate in this research project. I understand that participation is voluntary and that I may withdraw my consent at any time without penalty.

$\square$ I do not agree to participate and will be excluded from the remainder of the questions. 